\title{
Dinámica del manto de nieve en una pequeña cuenca de montaña mediterránea: el caso del río Tormes (Cuenca del Duero, España) ${ }^{1}$
}

\author{
Antonio Ceballos-Barbancho², José Manuel Llorente-Pinto³, \\ Esteban Alonso-González ${ }^{4}$ y Juan Ignacio López-Moreno ${ }^{5}$
}

\begin{abstract}
RESUMEN
Recientemente se ha generado una base de datos homogénea, para estudiar la dinámica espacio-temporal del manto de nieve en el territorio español peninsular, a partir de teledetección (AVHRR-NOAA y MODIS) y modelos de balance de energía (WRF-FSM). Estas series de datos utilizadas a escala regional presentan la incertidumbre de su aplicación en pequeñas cuencas de cabecera para comprender mejor la hidro-climatología de las mismas. Asumiendo la disparidad de técnicas aplicadas, y la diversidad de variables en las que se expresan las estimaciones (extensión superficial, dias con nieve, profundidad del manto y cantidad de agua equivalente), los resultados obtenidos permiten describir el comportamiento estacional del manto de nieve en la cuenca seleccionada, así como su marcada variabilidad interanual. También muestran que los datos de cubierta de nieve resultan menos útiles para el seguimiento hidrológico que las series modelizadas (WRFFSM), que informan del espesor y de la cantidad de agua equivalente.
\end{abstract}

Palabras clave: Cubierta de nieve, AVHRR-NOAA, MODIS, Modelo WRF-FSM, cuenca de montaña, mediterráneo.

\begin{abstract}
Recently, a homogeneous database has been generated to study the spatial-temporal dynamics of the snow cover in the Spanish peninsular territory, from remote sensing (AVHRR-NOAA and MODIS) and energy balance models (WRF-FSM). These data series used at regional scale show the uncertainty of their application in small headwaters to better understand the hydro-climatology of the same. Assuming the disparity of applied techniques, and the diversity of variables in which the estimates are expressed (snow cover, snow days, snow depth and snow water equivalent), the results obtained allow to describe the seasonal behavior of the snow cover in the study catchment, as well as its marked interannual variability. The results show that snow cover data are less useful for hydrological analysis than modeled series (WRF-FSM), which report the thickness and amount of snow water equivalent.
\end{abstract}

Keywords: Snow cover, AVHRR-NOAA, MODIS, FSM-WRF model, mountain catchment, Mediterranean.

\footnotetext{
La presente investigación ha sido posible gracias a los fondos de los proyectos IBERNIEVE (Referencia: CGL2014-52599-P) e HIDROIBERNIEVE (Referencia: CGL2017-82216-K) financiados por el Ministerio de Economía y Competitividad del Gobierno de España). Artículo recibido el 20 de diciembre de 2017, aceptado el 23 de abril de 2018 y corregido el 6 de junio de 2018.

Departamento de Geografía, Universidad de Salamanca (España).E-mail: ceballos@usal.es Departamento de Geografía, Universidad de Salamanca (España).E-mail: mane@usal.es

Instituto Pirenaico de Ecología, Consejo Superior de Investigaciones Científicas (España). E-mail: e.alonso@ipe.csic.es

Instituto Pirenaico de Ecología, Consejo Superior de Investigaciones Científicas (España). E-mail: nlopez@ipe.csic.es
} 
Por su situación y características geográficas la presencia de nieve en las montañas españolas es usual durante los meses invernales y primaverales, desempeñando un importante papel en la hidrometeorología de este ámbito espacial. En los últimos años varios estudios han manifestado la importancia del manto de nieve en diversos procesos de naturaleza física y socieconómica. Por ejemplo la relación entre la dinámica del manto de nieve y la ecología de zonas de montaña (Beniston et al., 2003, Barnett et al., 2005); la influencia de la nieve en la producción y estacionalidad de los caudales (López-Moreno \& García-Ruiz, 2004, Barnett et al., 2005, García-Ruiz et al., 2011, López-Moreno et al., 2011, Fayad et al., 2017) o la dependencia de la economía de ciertas zonas de montaña, basadas en un turismo especializado en la práctica de deportes de invierno, de la disponibilidad de nieve durante la estación invernal (Lasanta et al., 2007; Gilaberte-Burdalo et al., 2014).

A pesar de estas circunstancias, en el caso de España no existe una base de datos homogénea y distribuida por el territorio que permita analizar la disponibilidad, estacionalidad y evolución del manto de nieve. La única excepción la representa el programa ERHIN -Evaluación de los Recursos Hídricos procedentes de la Innivación- (Estrela y Francés, 2008), pero con series de datos en la mayoría de los casos cortas y discontinuas, circunstancia que dificulta la posibilidad de establecer cualquier tipo de conclusión. Por este motivo, en mayo de 2015 comenzó a desarrollarse el proyecto IBERNIEVE (Estudio del manto de nieve en la montaña española y su respuesta a la variabilidad y cambio climático), financiado por el Ministerio de Economía y Competitividad del Gobierno de España, siendo uno de sus principales objetivos generar una base de datos sobre el manto de nieve (superficie, espesor, densidad, período de innivación, etc.), a partir de distintas fuentes de información y con una resolución espacio-temporal variable. Teniendo en cuenta la extensión superficial de los sistemas montañosos españoles, las principales técnicas y/o fuentes de información utilizadas han sido los productos de teledetección (Dietz et al., 2012a) y la aplicación de modelos de balance de energía (Essery, 2015).

En el caso de la teledetección puede estimarse la superficie y duración del manto nival, pero con una notable incertidumbre sobre la cantidad de agua equivalente si se quiere analizar el impacto de la nieve en los recursos hídricos de un territorio. En los últimos años se han llevado a cabo una serie de trabajos, en diversas zonas de montaña a escala global, enfocados a medir la extensión del manto de nieve, la duración del período de innivación y la tendencia temporal de ambas variables, siempre en áreas de estudio con una extensión de varios miles de $\mathrm{km}^{2}$. La mayoría de los investigadores han utilizado los productos de la plataforma MODIS (Moderate Resolution Imaging Spectroradiometer), con una duración de los períodos de análisis limitada a las dos décadas del presente siglo, lo que condiciona la observación de cualquier tipo de tendencia significativa. En el contexto geográfico de Europa Dietz et al. (2012b) generaron una base de datos a escala continental para el período 2000-2011, analizando la cobertura de nieve y la fecha de inicio del período de fusión; mientras que Gascoin et al. (2015) se centraron en el sistema montañoso de Los Pirineos testando los productos Terra/MOD10A1 y Aqua/MYD10A1, con observaciones in situ, y concluyendo su precisión y fiabilidad para estudios aplicados de hidroclimatología. Un análisis parecido fue el realizado por Marchane et al. (2015) en el norte de África, concretamente en 7 cuencas situadas en el Atlas, observando una marcada variabilidad interanual en la extensión superficial y duración del manto de nieve. En Asia, una buena muestra la representan los estudios de Maskey et al. (2011) en la cordillera de Los Himalayas, en donde se analizaron series mensuales, estacionales y anuales de cobertura de nieve en diferentes bandas latitudinales para el período 2000-2008; Fayaz et al. (2013), en la extensa cuenca del río Karoun (Irán), observaron un ligero descenso no significativo de la superficie del manto de nieve en el período 2000-2012; Atif et 
al. (2015) enfocaron su análisis en la cuenca alta del río Indo en Pakistán a la estacionalidad del manto de nieve durante el período 2003-2013, apreciando un retraso importante en su fecha de inicio; mientras que Li et al. (2017), en las montañas Hengduan en el sur de China, no detectaron una tendencia temporal significativa en la extensión del manto de nieve pese a analizar una serie más larga (2000-2014). En América del Norte dos buenos ejemplos son los trabajos de Fassnacht et al. (2016), quienes estudiaron la correlación entre la superficie del manto nival medida con MODIS y la cantidad de agua equivalente medida con telenivometros en Wyoming y Colorado, con un especial énfasis en el análisis de las curvas de fusión; y de Verbyla et al. (2017), quienes se centraron en el seguimiento del límite altitudinal del manto nival en 28 áreas de montaña en Alaska y oeste de Canadá, observando una marcada relación entre la temperatura media de mayo, el total de lluvia invernal y la altitud del límite inferior del manto de nieve en primavera durante el período 2000-2016. Finalmente, en América del Sur, la gran mayoría de las investigaciones se han desarrollado en Los Andes, como puede comprobarse en los resultados y discusión de una serie de trabajos publicados recientemente. Sproles et al. (2016) desarrollaron un modelo hidrológico para estimar los caudales en el río Elqui en Chile, obteniendo los datos de fusión nival en Los Andes a partir de MODIS; Cornwell et al. (2016) estudiaron el pico de fusión nival en Los Andes chilenos y argentinos, combinando los datos de MODIS con los de un modelo de balance de energía; por su parte Stehr \& Aguayo (2017) analizaron la dinámica espacio-temporal del manto de nieve en 5 grandes cuencas en Los Andes chilenos en relación con el ENSO, observando una reducción no significativa de la cobertura nival en 3 de las 5 cuencas durante el período 2000-2016; finalmente, Saavedra et al. (2018) también estudiaron la dinámica del manto de nieve en Los Andes durante el período 2000-2016, apreciando una reducción significativa del período de innivación y un ascenso altitudinal del límite del manto de nieve, especialmente en la vertiente oriental, que relacionaron con un aumento de las temperaturas y un descenso de las precipitaciones.

De manera complementaria a la teledetección, con los modelos puede obtenerse una serie de variables clave, como la profundidad del manto de nieve o la cantidad de agua equivalente, para evaluar los recursos hídricos de un determinado territorio. En los últimos años se ha desarrollado una prolija línea de investigación con diferentes respuestas a los retos que suponen la propia escala de trabajo o el acoplamiento de modelos meteorológicos y modelos de balance de masa y energía. A modo de ejemplo pueden consultarse trabajos como el ya citado de Cornwell et al. (2016) en Los Andes; Wu et al. (2016) en los Montes Altai en el noroeste de China; van Pelt et al. (2016) en el archipiélago de las Svalbard (Noruega); Wrzesien et al. (2017) en Sierra Nevada (California) o Alonso-González et al. (2018) en el caso concreto de los sistemas montañosos de España peninsular y cuyos resultados serán utilizados en el presente artículo.

En este contexto, los primeros resultados del proyecto IBERNIEVE han permitido estudiar el grado de correlación de los datos procedentes de diversas fuentes y técnicas, y, una vez validados, analizar la dinámica espacio-temporal del manto de nieve a escala regional, bien para el conjunto de la España peninsular o bien comparando distintos sistemas montañosos, en unidades espaciales de miles de kilómetros cuadrados (Alonso-González et al., 2017, Navarro-Serrano et al., 2017, Llorente-Pinto et al., 2017). Con estos precedentes se nos plantea la pregunta de si estas bases de datos resultan apropiadas para estudiar la dinámica del manto de nieve en cuencas de cabecera de pequeño tamaño $\left(<100 \mathrm{~km}^{2}\right)$, de cara a completar la descripción hidrometeorológica de las mismas, y poder valorar la importancia de la nieve en la producción de agua. En ambientes mediterráneos las cuencas de cabecera, situadas generalmente en zonas de montaña, son vitales para la generación de caudales debido, por un lado, a la ocurrencia de precipitaciones más 
cuantiosas, y, por otro, a que una proporción variable de las mismas sea en forma de nieve, lo cual favorece el mantenimiento de los caudales durante los meses de menos lluvias o incluso ausencia de las mismas.

Así pues, el objetivo principal del presente trabajo es discutir la posibilidad de aplicar la información de bases de datos de nieve, utilizadas en análisis regionales (por ejemplo, en los grandes sistemas montañosos de la Península Ibérica), a una escala de mayor detalle (como es el caso de cuencas de cabecera en zonas de montaña, con una superficie inferior a los $100 \mathrm{~km}^{2}$ ). En relación con ello podríamos enumerar los siguientes objetivos específicos: i) Analizar el grado de correlación de los resultados obtenidos aplicando diferentes técnicas para la estimación del manto de nieve. ii) Delimitar la duración y estacionalidad de la cubierta de nieve en la cuenca seleccionada estimando el número medio de días con presencia de nieve al mes, la superficie del manto de nieve y la profundidad del mismo. iii) Evaluar la tendencia temporal del manto de nieve en un escenario de cambio global. iv) Discutir la probable influencia del manto de nieve en la generación de caudales en la cuenca seleccionada.

\section{Metodología}

La cuenca hidrográfica de Hoyos del Espino se localiza en la cara norte de la Sierra de Gredos (Sistema Central) y representa el tramo de cabecera del río Tormes, uno de los principales afluentes del río Duero por su margen izquierda (Figura $N^{\circ} 1$ ). Utilizando como referencia la estación de aforos de Hoyos del Espino, el área de drenaje es $66,44 \mathrm{~km}^{2}$, correspondiendo las siguientes coordenadas geográficas a su punto central: $40^{\circ} 19^{\prime} 58^{\prime \prime} \mathrm{N}-5^{\circ} 08^{\prime} 06^{\prime \prime} \mathrm{W}$. La altitud media de la cuenca es $1.633 \mathrm{~m} \mathrm{~s}$. n. m., oscilando en un rango comprendido entre 1.368 y $2.218 \mathrm{~m} \mathrm{s.} \mathrm{n.} \mathrm{m.}$ Estos datos, junto al hecho de que la mitad de su superficie esté por encima de los $1.600 \mathrm{~m} \mathrm{~s} . \mathrm{n}$. m. (Cuadro $N^{\circ} 1$ ), justifican con creces que pueda considerarse como una cuenca de montaña en el contexto geográfico de la Península Ibérica. Debido a su tamaño, carácter montañoso y a la circunstancia de que previamente haya sido estudiada su respuesta hidrológica (Ceballos-Barbancho y Morán-Tejeda, 2006, Ceballos-Barbancho et al. 2008), la cuenca de Hoyos del Espino representaba una buena opción para afrontar los objetivos de este trabajo expuestos en el apartado introductorio.

El sustrato litológico es bastante homogéneo, con el predominio de granitoides y leucogranitos del Hercínico y presencia de sedimentos del Cuaternario en los fondos de valle fluviales (gravas, arenas y limos). La precipitación anual media en la localidad de Hoyos del Espino, situada a $1.460 \mathrm{~m} \mathrm{s.} \mathrm{n.} \mathrm{m.,} \mathrm{es} 831 \mathrm{~mm}$ en el período 1951-2014, aunque es muy probable que sobrepase los $1.600 \mathrm{~mm}$ a partir de los $2.000 \mathrm{~m}$ de altitud. La ocurrencia de dos meses secos al año, con menos de $20 \mathrm{~mm}$ de precipitación media (julio y agosto), determina el carácter mediterráneo de la zona. La temperatura media anual oscila en torno a los $10,5^{\circ} \mathrm{C}$, siendo enero el mes más frío, con $3^{\circ} \mathrm{C}$ de temperatura media, y julio el más cálido, aunque sin superar los $20^{\circ} \mathrm{C}$. Por debajo de los 1.600 $\mathrm{m}$ de altitud predominan las manchas boscosas de pino albar (Pinus sylvestris), alternando con matorral de leguminosas (Cytisus multiflorus, C. scoparius, Genista cinerea, G. florida, etc.). Por encima de esa altitud los piornales de Cytisus oromediterraneus y los cambrionales de Echinospartum barnadessi ocupan buena parte del territorio, y a partir de los 1.800-1.900 m los pastizales de montaña con Festuca indigesta y Nardus stricta. 
Figura $N^{\circ} 1$

Mapa de la cuenca hidrográfica de Hoyos del Espino

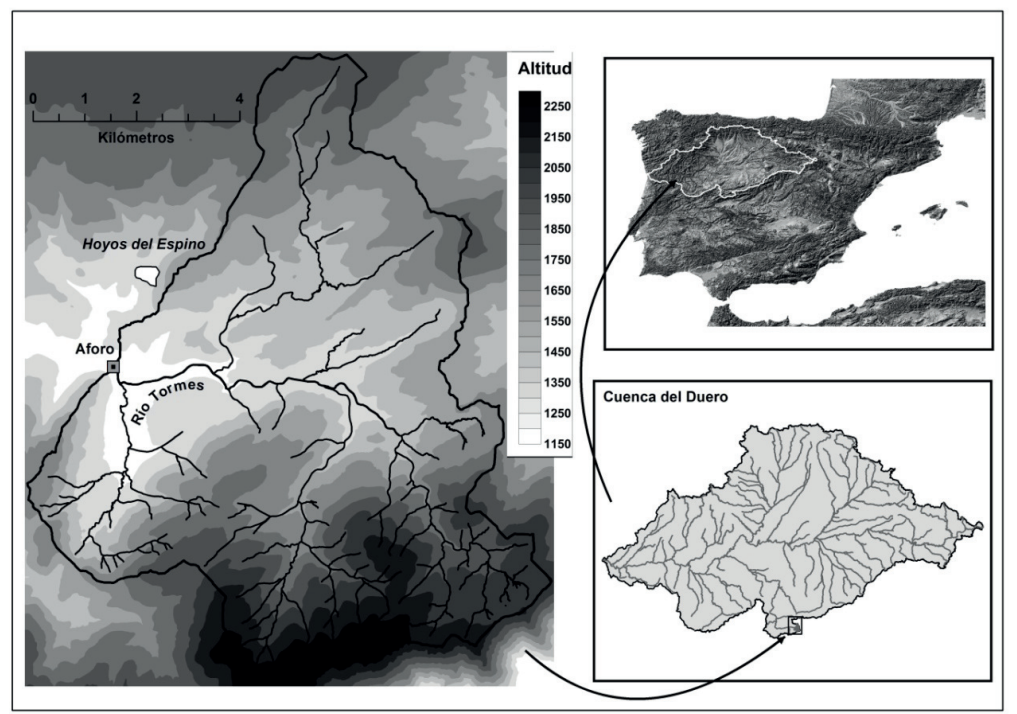

Fuente: Elaboración propia

Cuadro $N^{\circ} 1$

Distribución de la superficie de la cuenca a partir de determinados umbrales de altitud

\begin{tabular}{|c|c|c|c|c|c|c|c|c|c|c|c|}
\hline \multicolumn{2}{|c|}{$>1.500 \mathrm{~m}$} & \multicolumn{2}{|c|}{$>1.600 \mathrm{~m}$} & \multicolumn{2}{c|}{$>1.700 \mathrm{~m}$} & \multicolumn{2}{c|}{$>1.800 \mathrm{~m}$} & \multicolumn{2}{c|}{$>1.900 \mathrm{~m}$} & \multicolumn{2}{c|}{$>2.000 \mathrm{~m}$} \\
\hline $\mathrm{km}^{2}$ & $\%$ & $\mathrm{~km}^{2}$ & $\%$ & $\mathrm{~km}^{2}$ & $\%$ & $\mathrm{~km}^{2}$ & $\%$ & $\mathrm{~km}^{2}$ & $\%$ & $\mathrm{~km}^{2}$ & $\%$ \\
\hline 51,8 & 78,0 & 32,6 & 49,0 & 18,7 & 28,2 & 11,2 & 16,8 & 5,3 & 8,0 & 2,3 & 3,4 \\
\hline
\end{tabular}

Fuente: Elaboración propia.

\section{Estimación del manto de nieve mediante técnicas de teledetección}

Debido a la dificultad que entraña la medición directa del manto de nieve en sistemas montañosos, la teledetección es el principal instrumento disponible para estimar la extensión del manto de nieve, a pesar de algunos inconvenientes relacionados con la ocurrencia de topografías abruptas y masas de nubes (Dietz et al., 2012a). Las series de datos de sensores multiespectrales, utilizadas en el proyecto IBERNIEVE, proceden de las plataformas satelitales NOAA-AVHRR, MODIS y SPOT, con un tamaño de píxel variable entre 500 y 1.100 metros y una periodicidad comprendida entre 1 y 15 días.

La serie de imágenes del satélite NOAA-AVHRR comienza en julio de 1981 y finaliza en junio de 2009. La resolución espacial es de un píxel de 1,21 km², por lo que la cuenca seleccionada incluiría un total de 55 píxeles. La frecuencia de la información es quincenal, debido a lo cual en principio se dispondría de 672 quincenas distribuidas en 28 años. La proporción de quincenas sin 
datos válidos es muy variable en el caso de las montañas españolas, oscilando entre el 10\% en las montañas del sur del país y el $40 \%$ en el norte (Llorente-Pinto et al., 2017). Concretamente, en la cuenca seleccionada, ubicada en el Sistema Central, el porcentaje de quincenas sin datos fiables ha sido del 20,4\%. Esta base de datos fue generada por el Instituto Pirenaico de Ecología del Consejo Superior de Investigaciones Científicas de España, a partir de la adquisición y procesamiento de las imágenes de los satélites NOAA 7, 9, 11, 14, 16, 18 y 19 (Azorín-Molina et al., 2013).

La serie MODIS comienza en febrero de 2000 y continúa en la actualidad. La resolución espacial es de $0,25 \mathrm{~km}^{2}$, debido a lo cual en la cuenca seleccionada se incluiría un total de 266 píxeles. Para este trabajo se han utilizado los productos correspondientes a la versión 6 de MOD102A, que facilita información de síntesis para a un período de 8 días, y MOD1OA1-Snow Cover Daily L3 Global 500m Grid, con datos diarios de cobertura. En relación con NOAA, en principio mejora la resolución espacial de la información, la frecuencia temporal de la misma, y reduce la proporción de lagunas. En el caso del producto MOD102A y considerando el período comprendido entre el 19/02/2000 y el 21/09/2014, el porcentaje de imágenes descartadas ha sido el 11,4, que incluye tanto los casos de archivos sin datos (sólo 4) como las imágenes en las que las nubes ocupaban más del 8,9\% de la zona de estudio; mientras que en el caso del producto MOD10A1 se utilizó una serie completa sin lagunas tras aplicar el algoritmo de relleno generado por Gascoin et al. (2015). Las imágenes MODIS son elaboradas por el NSIDC (National Snow and Ice Data Center) y están disponibles en el portal electrónico de dicha institución ya corregidas y preparadas para su aplicación directa (Riggs et al., 2006; Hubanks et al., 2007; Riggs \& Hall, 2015).

Los datos procedentes del satélite SPOT comienzan en abril de 1998 y finalizan en mayo de 2014, con una resolución espacial de 1 km² y una periodicidad de 10 días. Las imágenes están disponibles en el portal http://www.vito-eodata.be/PDF/portal/Application.html\#Home y a diferencia de NOAA y MODIS no se trata de un producto acabado, ya que para la estimación de la cubierta se ha aplicado el índice normalizado de nieve (NDSII Normalized Difference Snow and Ice Index), propuesto inicialmente por Dozier (1989) y perfeccionado por otros autores (Xiao et al., 2001; Dankers \& De Jong, 2004), seleccionando un umbral de 0,37 para discriminar las superficies cubiertas por nieve. El principal problema que presentan estas imágenes es la aparición de una serie de bandas subverticales en la franja espectral del infrarrojo de onda corta que erróneamente pueden identificarse como cubierta de nieve (Llorente-Pinto et al., 2017).

En todos los análisis de teledetección realizados por el proyecto IBERNIEVE se ha considerado el territorio de la Península Ibérica situado por encima de los $1.000 \mathrm{~m} \mathrm{s.} \mathrm{n.} \mathrm{m.} \mathrm{para} \mathrm{descartar} \mathrm{falsos}$ positivos y asumiendo la realidad de que la cota habitual de nieve en las montañas españolas está claramente por encima de esa altitud. En el caso que se estudia en este trabajo, esta circunstancia no supone ningún problema ya que la altitud mínima de la cuenca es $1.368 \mathrm{~m} \mathrm{s.} \mathrm{n.} \mathrm{m.}$

Una valoración crítica de estas fuentes de información (productos acabados) debe considerar ciertas insuficiencias como errores en algunas imágenes, presencia de nubes que impiden detectar la señal de la nieve e incluso imperfecciones en los métodos utilizados para discriminar la superficie cubierta por nieve.

Todas las rutinas vinculadas al manejo de las imágenes se han realizado utilizando diferentes programas informáticos como QGIS, ArcGIS, Idrisi, Matlab o R. 


\section{Estimación del manto de nieve mediante la aplicación de un modelo de balance de energía}

La aplicación de modelos de balance de energía presenta un buen complemento a los resultados de la teledetección, ya que completan el dato de cobertura de nieve con información del espesor y del equivalente en agua en forma de nieve. En aquellas circunstancias que imposibiliten la adquisición de imágenes con la suficiente calidad (por ejemplo, una densa cobertura de nubes), puede suponer el único dato disponible sobre la dinámica del manto de nieve y, además, permite mejorar ostensiblemente la resolución temporal de las series.

La base de datos utilizada en este trabajo procede de una simulación del manto de nieve aplicando el modelo de balance de masa y energía Factorial Snow Model 1.0 (FSM) (Essery, 2015), a partir de los datos meteorológicos proporcionados por el modelo Weather Research and Forecasting (WRF) (Skamarock et al., 2008), usando como condiciones iniciales y de contorno los datos de reanálisis de ERA-Interim para el territorio español peninsular (Argüeso et al., 2012, García-Valdecasas-Ojeda et al., 2017). La resolución espacial de la información generada viene determinada por la del modelo WRF, que es de 9,78 x 9,78 km. Dentro de cada píxel es posible proyectar las salidas del WRF a intervalos altitudinales de $100 \mathrm{~m}$ utilizando gradientes de temperatura y ecuaciones higrobarométricas. Los nuevos datos meteorológicos se usaron como datos de entrada del modelo FSM produciendo simulaciones para cada uno de los rangos altitudinales. Las variables implicadas en la simulación son la radiación de onda larga, radiación de onda corta, humedad relativa, viento, tasa de precipitación sólida, tasa de precipitación líquida, presión atmosférica en superficie y temperatura. Una completa descripción de la metodología aplicada puede consultarse en Alonso-González et al. (2017, 2018).

La aplicación del WRF-FSM nos facilita a resolución diaria la presencia/ausencia de nieve en un píxel de $96 \mathrm{~km}^{2}$ expresada bien como espesor del manto en metros (SD = Snow Depth) o como cantidad de agua equivalente en mm (SWE = Snow Water Equivalent). A partir de los resultados del WRF-FSM hemos creado una serie de datos mensuales correspondientes al período comprendido entre el 1/08/1980 y el 30/11/2014 considerando las siguientes variables:

i. Número de días con presencia de nieve deducidos a partir de umbrales relativos a SD y SWE. En este trabajo se considera día con nieve aquel con un valor de $S D>0,11 \mathrm{~m}$ y de SWE $>40 \mathrm{~mm}$, en función de los límites que detecta MODIS publicados por Gascoin et al. (2015).

ii. Valor medio de la profundidad del manto de nieve y de la cantidad de agua equivalente.

iii. Valor máximo de la profundidad del manto de nieve y de la cantidad de agua equivalente.

\section{Análisis y comparación de datos}

En el caso de la teledetección, una vez extraídos los píxeles de cada sensor, incluidos dentro del perímetro de la cuenca, se procedió a la elaboración de series temporales de cobertura del manto de nieve con una duración variable. La comparación entre las series de datos de cubierta de nieve estimada con teledetección se hizo por medio de un análisis de correlación y regresión lineal no incluyendo los pares en los que en ambos meses el valor era igual a 0 (generalmente, salvo excepciones puntuales, entre junio y septiembre). También se descartaron aquellas imágenes en las que el porcentaje de No Data (ND) fuera superior al $10 \%$ de la superficie de la cuenca debido 
a factores como la nubosidad o problemas derivados de la corrección geométrica. Aunque este filtro redujo el número de casos para analizar; sin embargo, permitió eliminar las fuentes de error en las comparaciones. El período común entre las tres series de datos procedentes del NOAA, MODIS y SPOT se reduce al tiempo comprendido entre el 1 de septiembre de 2000 y el 30 de junio de 2009, un período de 106 meses que pueden agruparse en 9 años hidrológicos.

Con el objetivo principal de generar información sobre la estacionalidad y dinámica temporal del manto de nieve en la cuenca seleccionada, para completar la información hidroclimática existente referida a temperaturas, precipitaciones y caudales, se procedió a la elaboración de series mensuales con la cobertura media del manto de nieve a partir de las imágenes anteriores, corrigiendo o rellenando las lagunas en las fechas en las que los valores sin datos superaban el $10 \%$ de las celdas incluidas dentro del perímetro de la cuenca. Cuando no había ningún dato, el relleno se ha realizado por interpolación lineal eligiendo el valor más conservador dentro de los que parecían más razonables. Cuando había datos válidos, se ha asumido que los datos faltantes se distribuían de manera proporcional al número de celdas con nieve y sin nieve. No obstante, este resultado se comparaba con el obtenido por la interpolación lineal seleccionándose también el dato más conservador (Llorente-Pinto et al., 2017).

Para comparar las series de datos simuladas con WRF-FSM con las de los sensores de teledetección se consideró $1.700 \mathrm{~m}$ una altitud adecuada por varias razones: i) es la primera banda de $100 \mathrm{~m}$ situada por encima del valor de altitud media de la cuenca; ii) por encima de $1.700 \mathrm{~m}$ se extiende más de una cuarta parte de la superficie de la cuenca; y iii) representa un espacio intermedio entre dos escenarios extremos (años de nevadas copiosas, que cubren toda la cuenca, y años con muy poca nieve en las cotas más altas o incluso sin nieve). Los datos correspondientes a esta banda altitudinal reflejan de manera muy creíble, como analizaremos posteriormente, el reparto estacional y la dinámica interanual de los días de nieve en la zona de estudio.

\section{Análisis hidrológico}

Para estudiar la influencia del manto nival en la respuesta hidrológica de la cuenca se han analizado las series de datos mensuales de precipitaciones y caudales correspondientes a los meses de marzo-junio, que es el momento en el cual es posible apreciar el efecto de la fusión nival sobre los caudales en el área de estudio. Los registros de precipitaciones proceden de la estación de la AEMET (Agencia Estatal de Meteorología) en Hoyos del Espino y, tras la reconstrucción de las lagunas a partir de los datos de la cercana estación de Navalonguilla, se dispone de una serie completa para al período 1951-2014. Los datos de aportaciones hídricas proceden de la estación de aforos de Hoyos del Espino perteneciente a la CHD (Confederación Hidrográfica del Duero) y cumplen con las tres exigencias que Sanmiguel-Vallelado et al. (2016) proponen para analizarla como ejemplo de serie sensible al efecto del manto de nieve sobre el régimen hídrico:

i. Que al menos 25 años hidrológicos sean consecutivos con menos de un $5 \%$ de lagunas para el total de la serie. La serie actual comprende el periodo de 74 años entre 1940-41 y 2013-14. De los 888 meses que integran la serie, no hay datos en 39 (4,4\%).

ii. Que la mitad de las aportaciones anuales se produzcan entre los meses de marzo y junio, hecho que ocurre en la zona de estudio, considerando la serie histórica, y que manifiesta la importancia de la fusión nival sobre el régimen del río. 
iii. Finalmente, que la cuenca vertiente no tenga ninguna infraestructura que afecte al régimen natural del río, circunstancia que también ocurre en la zona seleccionada.

En relación con el manto de nieve, las variables analizadas han sido la superficie de la cubierta de nieve en el mes de marzo a $2.000 \mathrm{~m} \mathrm{~s}$. n. m. estimadas con NOAA y MODIS y la cantidad de SWE estimada con el modelo WRF-FSM. Las características geográficas del sistema montañoso en donde se localiza la cuenca determinan que la mayor constancia interanual del manto de nieve ocurra a $2.000 \mathrm{~m} \mathrm{s.} \mathrm{n.} \mathrm{m.,} \mathrm{lo} \mathrm{cual} \mathrm{implica} \mathrm{disponer} \mathrm{de} \mathrm{datos} \mathrm{de} \mathrm{nieve} \mathrm{en} \mathrm{los} \mathrm{años} \mathrm{de} \mathrm{menor} \mathrm{inniva-}$ ción, aspecto crucial para estudiar las anomalías en la relación precipitación-caudal (P vs. Q). Para poder comparar los datos mensuales de precipitación, caudal, cubierta de nieve y SWE, y analizar su grado de correlación a lo largo del tiempo, se han normalizado aplicando el índice F, que consiste en restar a cada dato mensual la media del conjunto del período de observación y dividir el resultado por la desviación estándar. El resultado de esta operación es un índice sintético cuyo valor 0 correspondería a aquellos meses con un valor similar a la media (Beguería et al., 2003). La dependencia entre variables se ha determinado aplicando correlaciones lineales y analizando los residuos de las mismas (López-Moreno \& García-Ruiz, 2004).

\section{Comparación de las imágenes NOAA, MODIS y SPOT y caracterización del régimen estacional y dinámica temporal del manto de nieve a partir de la teledetección}

Antes de proceder a la elaboración de las series mensuales de superficie del manto de nieve se compararon entre sí aquellas imágenes correspondientes a fechas similares y sin ningún tipo de error debido a la cobertura de nubes, según se explicó en el apartado previo. Ello permitió observar la significación estadística de los coeficientes de correlación y la existencia o no de un sesgo importante en los datos según su procedencia. Los datos del Cuadro $N^{\circ} 2$ muestran que la mejor correlación entre sensores se produce entre NOAA y MODIS, teniendo en cuenta todos los estadísticos manejados. Las peores correlaciones ocurren con el sensor del SPOT, que además tiende a infraestimar la superficie de nieve cuando se lo compara con NOAA y MODIS. El producto MODIS es el que mejor se correlaciona con los dos sensores restantes, tendiendo siempre a registrar valores mayores en la estimación de la superficie del manto de nieve.

Cuadro $\mathrm{N}^{\circ} 2$

Análisis de correlación y sesgo entre las imágenes válidas de los sensores NOAA, MOD102A y SPOT considerando los períodos comunes

\begin{tabular}{|l|c|c|c|r|r|}
\hline Sensores & Período común & \multicolumn{1}{|c|}{$\mathrm{N}$} & $\mathrm{R}^{2}$ & Sesgo $\left(\mathrm{km}^{2}\right)$ & Error medio \\
\hline NOAA vs MOD102A & $19 / 02 / 00-15 / 06 / 09$ & 104 & $0,722^{* *}$ & $-3,33$ & 3,33 \\
\hline NOAA vs SPOT & 01/04/98 - 15/06/09 & 71 & $0,671^{* *}$ & 11,45 & 18,76 \\
\hline SPOT vs MOD102A & $19 / 02 / 00-21 / 09 / 14$ & 265 & $0,625^{* *}$ & $-8,59$ & 13,96 \\
\hline
\end{tabular}

Fuente: Elaboración propia. ${ }^{* *}$ : valor-p $<0,01$. 
La Figura № 2 muestra la correlación entre los valores medios mensuales de las distintas series con un número de pares variable dependiendo del período de medición de cada sensor (ver Cuadro $N^{\circ} 2$ ). Los valores están expresados en porcentaje de cobertura de nieve debido al diferente tamaño de píxel de cada sensor, ya que el valor máximo posible de cubierta de nieve en $\mathrm{km}^{2}$, correspondiente al $100 \%$ de la superficie de la cuenca, oscilaba entre $70,18 \mathrm{~km}^{2}$ medidos por NOAA y $66,44 \mathrm{~km}^{2}$ medidos por MODIS. La mejor correlación se produce entre los productos de NOAA y MODIS, con un coeficiente de determinación significativo $(p<0.01)$ igual a 0,77 y un menor sesgo entre sensores. En el gráfico se aprecia que en aquellos meses en los que la cubierta de nieve es inferior al $20 \%$ de la superficie de la cuenca MODIS estima valores superiores de cubierta del manto de manera sistemática, debido muy probablemente al menor tamaño del píxel que magnifica el efecto borde. Sin embargo, en coherencia con esta apreciación, cuando la cobertura del manto de nieve es superior al $80 \%$ de la cuenca, es el sensor NOAA el que estima superficies de mayor extensión. En la correlación entre NOAA y SPOT el valor de $\mathrm{R}^{2}$ también es alto, pero con una clara tendencia de SPOT a infraestimar la superficie del manto de nieve en la mayoría de los meses. El coeficiente de determinación más bajo se observa entre los sensores MODIS y SPOT debido a la tendencia del primero a sobreestimar la extensión del manto de nieve y del segundo a infraestimarla, resultando llamativo que haya un número considerable de meses en los que MODIS estima una cubierta de nieve superior al $20 \%$ de la superficie de la cuenca mientras que SPOT no detecta presencia de nieve. Considerando los 113 meses correspondientes al período común de medición de los 3 sensores (19/02/2000-30/06/2009) MODIS detecta presencia de nieve en el 71,2\% de los meses con una superficie media igual a 10,68 $\mathrm{km}^{2}$. La superficie media de NOAA es 9,21 $\mathrm{km}^{2}$ y el porcentaje de meses 46 . SPOT detecta presencia de nieve sólo en el $38,1 \%$ de los meses y la superficie media se reduce a $4,35 \mathrm{~km}^{2}$. Mientras la diferencia entre la superficie media estimada con MODIS y NOAA es de un $13,8 \%$, la diferencia entre MODIS y SPOT es del $59,3 \%$.

Figura $\mathrm{N}^{\circ} 2$

Correlaciones lineales entre las series mensuales de cobertura de nieve a partir de las estimaciones de los sensores NOAA, MOD102A y SPOT
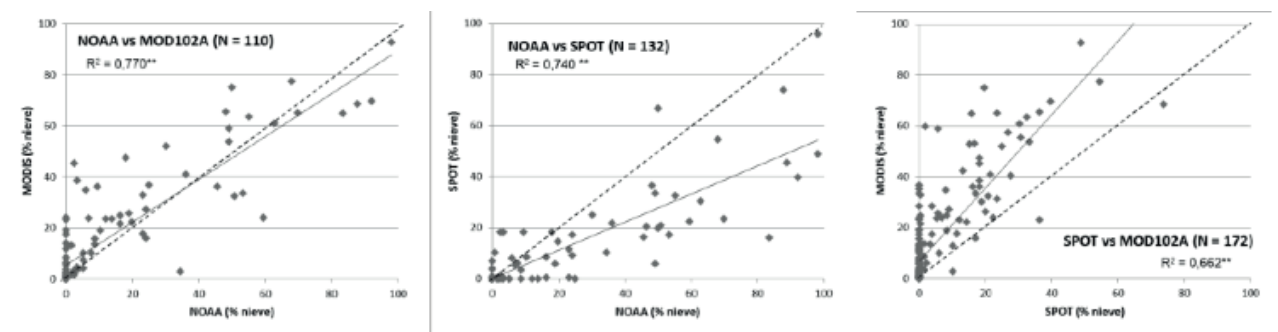

Fuente: Elaboración propia. ${ }^{* *}$ : valor-p $<0,01$.

Los resultados anteriores confirman lo apuntado por Llorente-Pinto et al. (2017), para el conjunto del territorio español peninsular, quienes observan que los valores procedentes de los productos acabados NOAA y MODIS promedian extensiones de nieve mayores que los procedentes del SPOT, que requieren la aplicación del NDSII. Este dato, junto a la mayor correlación y menor sesgo entre NOAA y MODIS, invitan a considerar las series de NOAA y MODIS como más realistas, y por tanto más adecuadas, para a partir de ellas analizar la estacionalidad y dinámica de la nieve 
en la cuenca. Mientras que MODIS tiene la garantía de que ha sido un producto muy utilizado y testado en diversos ámbitos espaciales para estudiar la dinámica de la nieve y el hielo (por ejemplo: Maskey et al., 2011; Stehr et al., 2011; Dietz et al., 2012b, Fayaz et al., 2013; Gascoin et al., 2015; Atif et al., 2015; Li et al., 2017; Sterh \& Aguayo, 2017; Verbyla et al., 2017 o Saavedra et al., 2018), NOAA ofrecería la ventaja de disponer de una serie más larga de datos (28 años). En su análisis de la disparidad de resultados observada entre NOAA, MODIS y SPOT en las montañas españolas peninsulares, Llorente-Pinto et al. (2017) sugieren que las diferencias pueden explicarse por los distintos criterios adoptados para el análisis de las imágenes, la diversidad de procedimientos y algoritmos, las características radiométricas de los sensores, la frecuencia temporal de las imágenes y su resolución espacial.

Cuadro $\mathrm{N}^{\circ} 3$

Superficie de nieve media mensual estimada con NOAA, MODIS y SPOT $\left(\mathrm{km}^{2}\right)$

\begin{tabular}{|l|r|r|r|r|r|r|r|r|r|r|r|r|}
\hline $\begin{array}{l}\text { MODIS } \\
\begin{array}{l}\text { 2000-01/ } \\
\text { 2013-14 }\end{array}\end{array}$ & Oct & Nov & Dic & Ene & Feb & Mar & Abr & May & Jun & Jul & Ago & Sep \\
\hline Media & 3,07 & 14,92 & 27,96 & 26,16 & 30,00 & 13,88 & 4,39 & 0,98 & 0,22 & 0,00 & 0,00 & 1,00 \\
\hline STD & 3,0 & 9,1 & 14,5 & 13,0 & 14,6 & 9,5 & 3,6 & 1,2 & 0,5 & 0,0 & 0,0 & 1,4 \\
\hline C.V. (\%) & 98,4 & 61,3 & 51,7 & 49,6 & 48,8 & 68,1 & 82,6 & 120,2 & 223,8 & - & - & 142,1 \\
\hline Prob* & 0,71 & 1,00 & 1,00 & 1,00 & 1,00 & 1,00 & 0,93 & 0,71 & 0,29 & 0,00 & 0,00 & 0,64 \\
\hline $\begin{array}{l}\text { NOAA } \\
\text { 1981-82/ } \\
\text { 2008-09 }\end{array}$ & Oct & Nov & Dic & Ene & Feb & Mar & Abr & May & Jun & Jul & Ago & Sep \\
\hline Media & 3,52 & 5,90 & 15,04 & 30,83 & 28,24 & 18,65 & 4,71 & 0,71 & 0,04 & 0,00 & 0,00 & 0,13 \\
\hline STD & 7,7 & 7,4 & 15,0 & 21,2 & 21,6 & 16,9 & 5,7 & 1,2 & 0,2 & 0,0 & 0,0 & 0,3 \\
\hline C.V. (\%) & 217,5 & 125,8 & 99,7 & 68,8 & 76,5 & 90,5 & 120,3 & 165,0 & 529,2 & - & - & 265,1 \\
\hline Prob* & 0,46 & 0,75 & 0,90 & 0,96 & 0,93 & 0,90 & 0,71 & 0,43 & 0,04 & 0,00 & 0,00 & 0,14 \\
\hline $\begin{array}{l}\text { SPOT } \\
\text { 1998-99/ }\end{array}$ & Oct & Nov & Dic & Ene & Feb & Mar & Abr & May & Jun & Jul & Ago & Sep \\
2013-14 & & & & & & & & & & & & \\
\hline Media & 0,00 & 2,88 & 7,63 & 13,28 & 16,19 & 9,65 & 1,37 & 0,02 & 0,00 & 0,00 & 0,00 & 0,00 \\
\hline STD & 0,0 & 5,1 & 10,1 & 18,2 & 13,0 & 7,7 & 2,4 & 0,1 & 0,0 & 0,0 & 0,0 & 0,0 \\
\hline C.V. (\%) & - & 175,5 & 132,4 & 137,0 & 80,5 & 79,9 & 178,6 & 400,0 & - & - & - & - \\
\hline Prob* & 0,00 & 0,44 & 0,56 & 0,88 & 0,88 & 0,81 & 0,56 & 0,06 & 0,00 & 0,00 & 0,00 & 0,00 \\
\hline
\end{tabular}

Fuente: Elaboración propia. Prob*: Probabilidad en tantos por uno.

Con las series mensuales estimadas con la teledetección puede analizarse la estacionalidad del manto de nieve en la cuenca de cabecera del río Tormes (Cuadro $N^{\circ} 3$ ), comprobándose la importancia del período comprendido entre los meses de diciembre y marzo por dos razones. Con independencia de la diferencia entre sensores, en esos cuatro meses la extensión del manto de nieve es notable y registra valores que triplican en muchos casos la media anual y que, en 
su conjunto, representan al menos el $80 \%$ de la distribución del manto de nieve durante todo el año. Además, son los meses en los que se observa una menor variabilidad interanual, a pesar de que los coeficientes de variación sean todos muy elevados. Si consideramos las series de MODIS y NOAA, en estos meses la probabilidad de que aparezca nieve en la cuenca es $\geq 90 \%$. La única excepción a las afirmaciones previas es el mes de noviembre, en el caso del sensor MODIS, ya que estima una extensión media ligeramente superior a marzo y un coeficiente de variación algo menor, además de tener una probabilidad del $100 \%$ de que haya nieve en la superficie de la cuenca. Comparando estos resultados con los publicados en referencia a las montañas españolas, el sistema montañoso más estudiado es el pirenaico, en donde a partir de los 1.600-1.700 $\mathrm{m}$ la presencia continua de un manto de nieve de extensión variable ocurre entre los meses de noviembre y abril, siendo los meses de mayor acumulación los tres centrales del invierno (diciembre, enero y febrero) (Estrela y Francés, 2008; López-Moreno et al., 2011). La menor latitud y altitud del Sistema Central, en comparación con Los Pirineos, explica la duración más corta del período de innivación, debido fundamentalmente al aumento de las temperaturas en el mes de marzo y a la fusión rápida de la nieve acumulada durante el invierno (Ceballos-Barbancho et al., 2008; Estrela y Francés, 2008).

Aunque la duración de las series de datos de los distintos sensores sea desigual, permiten evaluar el comportamiento interanual de la superficie de nieve en la cuenca estudiada, en el actual escenario de cambio climático, con el propósito de observar el alcance de las anomalías durante los meses de invierno y la posible ocurrencia de tendencias interanuales para el conjunto de las series. En la Figura $N^{\circ} 3$ queda manifiesta la acusada irregularidad interanual del proceso de innivación en la cuenca alta del Tormes debido a lo cual los ajustes lineales de las tres series no muestran ningún tipo de tendencia significativa, con valores de Rs (coeficiente de correlación de Spearman) próximos a 0.

Figura $\mathrm{N}^{\circ} 3$

Evolución de la superficie de nieve media mensual estimada con NOAA, MODIS y SPOT $\left(\mathrm{km}^{2}\right)$ y líneas de tendencia

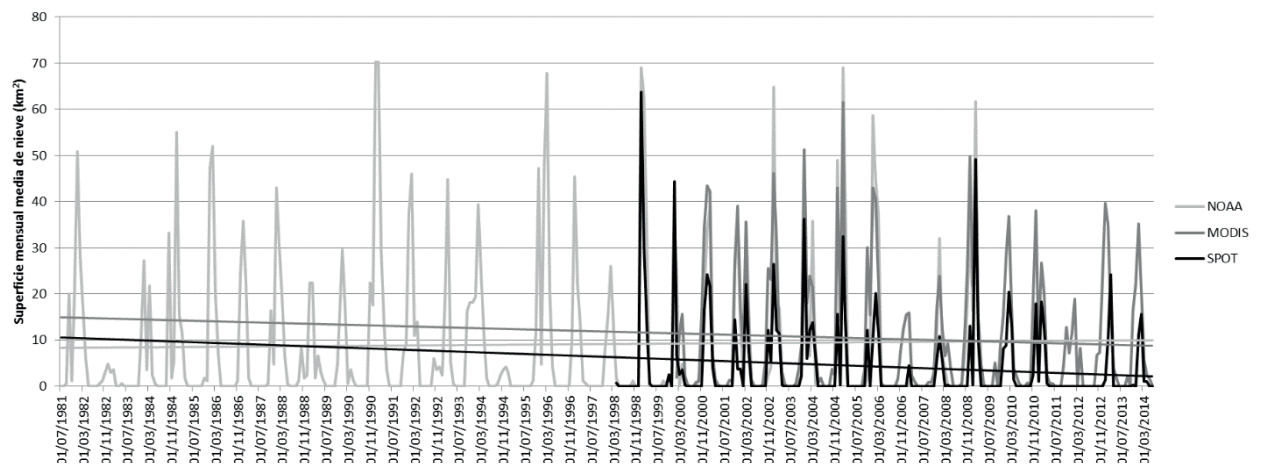

Fuente: Elaboración propia.

En relación con la distribución estacional del manto de nieve ilustrada en el Cuadro $N^{\circ} 3$ y la evolución que aparece en la Figura №3, convendría analizar la tendencia temporal de los 4 meses de mayor innivación por su papel determinante en la hidrometeorología del espacio selecciona- 
do. En principio los resultados obtenidos no son estrictamente comparables porque proceden de sensores distintos $y$, sobre todo, porque difieren notablemente en la duración y solapamiento de la serie (Figura $\mathrm{N}^{\circ} 4$ ). La duración de NOAA es de 334 meses mientras que la de MODIS es de 178. El número de meses en el que ambas series se solapan es de tan sólo 113. Además este solapamiento no afecta a los últimos 65 meses del MODIS, que son determinantes en las tendencias negativas observadas en las series procedentes de este sensor. Las tendencias estimadas por ambos sensores son contrarias con la excepción del mes de enero y ninguna de ellas tiene un Rs significativo. No obstante, en el caso de MODIS sí debería señalarse que en los cuatro meses de mayor innivación se observa una tendencia negativa en los primeros 14 años del presente siglo, aunque no sea estadísticamente significativa, y el hecho de que sea más acusada en los meses de diciembre y marzo, con una Rs más alta, apunta a una posible contracción del período de nieve en la cuenca estudiada.

A escala global muy pocos análisis concluyen en la observación de tendencias estadísticamente significativas, incluso algunos resultados son contradictorios a la hora de establecer una tendencia general, debido en buena parte a la corta duración de las series y a la alta variabilidad interanual de los datos analizados (Maskey et al., 2011, Fayaz et al., 2013, Marchane et al., 2015, Li et al., 2017, Stehr \& Aguayo, 2017, Verbyla et al., 2017). Además, en el estudio de las tendencias temporales, trabajos como el de Buisan et al. (2016) muestran, en el caso de Los Pirineos, que cuando se analizan series de datos con un inicio posterior a 1980 no se aprecia tendencias

Figura $\mathrm{N}^{\circ} 4$

Evolución de la superficie de nieve media mensual estimada con NOAA y MODIS (\%) en los 4 meses de mayor innivación
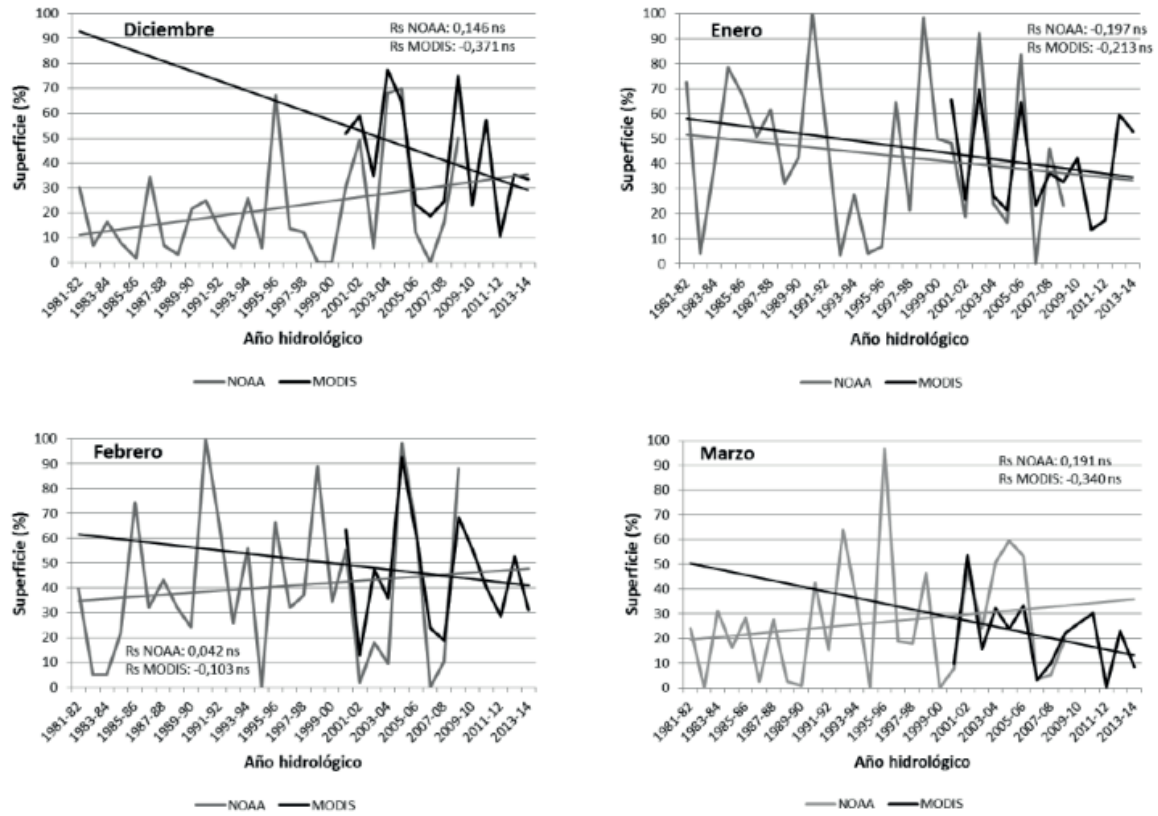

Fuente: Elaboración propia. ns: no significativo. 
con significación estadística debido al incremento de la frecuencia de inviernos con anomalías negativas de la NAO a partir de finales de la década de 1990. Llorente-Pinto et al. (2017) tampoco encuentran una tendencia con significación estadística del manto de nieve en el conjunto de la España peninsular en las tres últimas décadas, observando además un comportamiento distinto según el sistema montañoso que se estudie. Estas contradicciones y la dificultad para solapar las series de NOAA y MODIS invitan a ser muy prudentes a la hora de realizar cualquier tipo de conclusión mínimamente consistente sobre la tendencia temporal del manto de nieve en la cuenca seleccionada a partir de la teledetección.

\section{Estacionalidad y dinámica del manto de nieve a partir del modelo WRF-FSM}

Junto a la teledetección, las series de datos simuladas a partir del modelo WRF-FSM representan una fuente de información complementaria sobre la profundidad del manto de nieve (SD), la cantidad de agua equivalente (SWE) y, aplicando determinados umbrales en estas dos variables, el número de días con presencia de nieve en la cuenca. La Figura $N^{\circ} 5$ refleja la correlación entre el número medio mensual de días con nieve y la profundidad media mensual del manto, simulados con WRF-FSM para la banda de $1.700 \mathrm{~m}$, con un coeficiente de determinación significativo. Por un lado se aprecia que en aquellos meses en los que el número de días con presencia de nieve supera la decena, es posible que la profundidad media del manto de nieve registre valores medios por encima de los $20 \mathrm{~cm}$, y por otro la capacidad del modelo para estimar con valores muy creíbles la única gran nevada que se ha producido durante el período de análisis y de la que tenemos constancia documental, la denominada "gran nevada de enero de 1996" (Disponible en Internet: http://recmountain.com/la-gran-nevada-de-1996-iiii/). Según el modelo, en enero de 1996 a 1.700 $\mathrm{m}$ se registraron 18 días con nieve y el espesor medio del manto de nieve fue de casi $70 \mathrm{~cm}$. Consultando los datos de la AEMET (Agencia Estatal de Meteorología), este mes en concreto ha sido el enero más lluvioso de la serie histórica, con $439 \mathrm{~mm}$ de los cuales una buena proporción fueron de nieve. La acumulación de nieve se prolongó en febrero, en donde el modelo estima una profundidad media para todo el mes de $123 \mathrm{~cm}$, con máximos que superaron los $200 \mathrm{~cm}$. La persistencia de la nieve se prolongó en marzo, con una profundidad media de $85 \mathrm{~cm}$. En abril el proceso de fusión fue rápido, ya que la profundidad media del manto se redujo a $12,5 \mathrm{~cm}$ y el número de días con nieve a 11. Según el modelo, entre enero y abril de 1996 se produjo un período de innivación de 89 días consecutivos a $1.700 \mathrm{~m}$, alcanzándose los máximos espesores de toda la serie. Los tres outliers que destacan en la nube de puntos de la Figura $N^{\circ} 6$ corresponden a los meses de enero, febrero y marzo de 1996.

El Cuadro $N^{\circ} 4$ muestra el número medio mensual y total anual de días con nieve estimado por el modelo WRF-FSM para diferentes intervalos altitudinales, apreciándose que conforme aumenta la altitud el número y frecuencia de días con nieve es mayor y su variabilidad interanual menor. Si analizamos el resultado correspondiente a la banda de $1.700 \mathrm{~m}$, queda muy bien definido el período de innivación entre diciembre y marzo, con casi el $100 \%$ de los 23,5 días de nieve que el modelo estima para el conjunto del año. A partir de $2.000 \mathrm{~m} \mathrm{s.} \mathrm{n.} \mathrm{m.} \mathrm{el} \mathrm{número} \mathrm{anual} \mathrm{de} \mathrm{días} \mathrm{de}$ nieve se eleva a 83,4 días anuales, comenzando las nevadas en noviembre y prolongándose la presencia del manto hasta abril. 
Figura $\mathrm{N}^{\circ} 5$

Análisis de correlación entre el número mensual de días con nieve y la profundidad media del manto a partir del WRF-FSM a $1.700 \mathrm{~m} \mathrm{s.} \mathrm{n.} \mathrm{m.}$

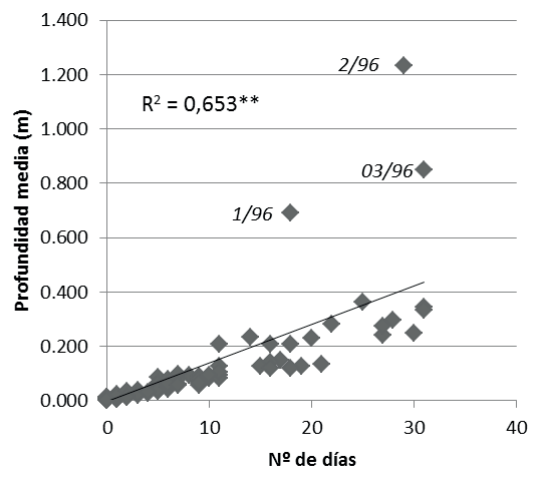

Fuente: Elaboración propia. ${ }^{* *}$ : valor-p $<0,01$.

La evolución de una serie de variables extraídas del modelo WRF-FSM, como el número mensual de días con nieve, SD mensual media y SD mensual máxima a $1.700 \mathrm{~m}$, no muestra ningún tipo de tendencia, como ya observáramos en el caso de la superficie de nieve estimada con teledetección, quedando manifiesta de nuevo la acusada variabilidad interanual de los valores analizados (Figura $N^{\circ} 6$ ). Centrando el análisis en las series correspondientes a los 4 meses de mayor innivación, hemos encontrado el mismo comportamiento: ausencia de cualquier tipo de tendencia temporal y una marcada variabilidad interanual.

\section{Cuadro $N^{\circ} 4$}

Media, desviación estándar y coeficiente de variación de las series mensuales y anuales de días con nieve por intervalos altitudinales obtenidas con el FSM-WRF para el período 1980-81/2013-14

\begin{tabular}{|l|r|r|r|r|r|r|r|r|r|r|r|r|r|}
\hline $1.500 \mathrm{~m}$ & Oct & Nov & Dic & Ene & Feb & Mar & Abr & May & Jun & Jul & Ago & Sep & Año \\
\hline Media & 0,00 & 0,06 & 1,15 & 2,41 & 3,32 & 0,85 & 0,03 & 0,00 & 0,00 & 0,00 & 0,00 & 0,00 & 7,82 \\
\hline STD & 0,00 & 0,34 & 2,13 & 3,84 & 5,84 & 2,11 & 0,17 & 0,00 & 0,00 & 0,00 & 0,00 & 0,00 & 9,59 \\
\hline C.V. (\%) & & 583,1 & 186,0 & 159,2 & 175,7 & 246,8 & 583,1 & - & - & - & - & - & 122,6 \\
\hline Prob* & 0,00 & 0,03 & 0,29 & 0,44 & 0,53 & 0,21 & 0,03 & 0,00 & 0,00 & 0,00 & 0,00 & 0,00 & 0,85 \\
\hline 1.600 m & Oct & Nov & Dic & Ene & Feb & Mar & Abr & May & Jun & Jul & Ago & Sep & Año \\
\hline Media & 0,00 & 0,09 & 2,15 & 4,12 & 4,26 & 1,82 & 0,03 & 0,00 & 0,00 & 0,00 & 0,00 & 0,00 & 12,47 \\
\hline STD & 0,00 & 0,38 & 3,10 & 5,92 & 6,29 & 5,48 & 0,17 & 0,00 & 0,00 & 0,00 & 0,00 & 0,00 & 13,88 \\
\hline C.V. (\%) & - & 429,3 & 144,2 & 143,7 & 147,5 & 300,5 & 583,1 & - & - & - & - & - & 111,3 \\
\hline Prob* & 0,00 & 0,06 & 0,41 & 0,50 & 0,68 & 0,24 & 0,03 & 0,00 & 0,00 & 0,00 & 0,00 & 0,00 & 0,88 \\
\hline 1.700 m & Oct & Nov & Dic & Ene & Feb & Mar & Abr & May & Jun & Jul & Ago & Sep & Año \\
\hline Media & 0,00 & 0,18 & 4,24 & 8,88 & 6,94 & 2,71 & 0,59 & 0,00 & 0,00 & 0,00 & 0,00 & 0,00 & 23,53 \\
\hline STD & 0,0 & 0,5 & 6,5 & 10,2 & 8,1 & 6,6 & 1,9 & 0,0 & 0,0 & 0,0 & 0,0 & 0,0 & 22,3 \\
\hline
\end{tabular}


Continuación Cuadro $N^{\circ} 4$

\begin{tabular}{|l|r|r|r|r|r|r|r|r|r|r|r|r|r|}
\hline C.V. (\%) & $-259,9$ & 153,4 & 115,0 & 116,8 & 244,0 & 329,8 & - & - & - & - & - & 94,7 \\
\hline Prob* & 0,00 & 0,15 & 0,50 & 0,71 & 0,71 & 0,35 & 0,21 & 0,00 & 0,00 & 0,00 & 0,00 & 0,00 & 0,88 \\
\hline $1.800 \mathrm{~m}$ & Oct & Nov & Dic & Ene & Feb & Mar & Abr & May & Jun & Jul & Ago & Sep & Año \\
\hline Media & 0,06 & 0,35 & 5,94 & 13,35 & 12,97 & 4,91 & 1,56 & 0,00 & 0,00 & 0,00 & 0,00 & 0,00 & 39,15 \\
\hline STD & 0,34 & 0,81 & 7,36 & 12,46 & 10,32 & 7,94 & 3,64 & 0,00 & 0,00 & 0,00 & 0,00 & 0,00 & 30,78 \\
\hline C.V. (\%) & 583,1 & 230,1 & 123,8 & 93,3 & 79,5 & 161,6 & 233,8 & - & - & - & - & - & 78,6 \\
\hline Prob* & 0,03 & 0,18 & 0,53 & 0,77 & 0,85 & 0,56 & 0,38 & 0,00 & 0,00 & 0,00 & 0,00 & 0,00 & 0,91 \\
\hline 1.900 m & Oct & Nov & Dic & Ene & Feb & Mar & Abr & May & Jun & Jul & Ago & Sep & Año \\
\hline Media & 0,06 & 1,32 & 7,94 & 17,65 & 18,65 & 11,24 & 3,15 & 0,03 & 0,00 & 0,00 & 0,00 & 0,00 & 60,03 \\
\hline STD & 0,34 & 2,41 & 8,28 & 12,69 & 11,41 & 10,44 & 6,93 & 0,17 & 0,00 & 0,00 & 0,00 & 0,00 & 39,45 \\
\hline C.V. (\%) & 583,1 & 182,0 & 104,3 & 71,9 & 61,2 & 92,9 & 220,3 & 583,1 & - & - & - & - & 65,7 \\
\hline Prob* & 0,03 & 0,38 & 0,68 & 0,88 & 0,85 & 0,74 & 0,44 & 0,03 & 0,00 & 0,00 & 0,00 & 0,00 & 0,97 \\
\hline 2.000 m & Oct & Nov & Dic & Ene & Feb & Mar & Abr & May & Jun & Jul & Ago & Sep & Año \\
\hline Media & 0,09 & 2,44 & 11,68 & 20,94 & 20,65 & 19,82 & 6,94 & 0,88 & 0,00 & 0,00 & 0,00 & 0,00 & 83,44 \\
\hline STD & 0,4 & 4,5 & 11,7 & 12,7 & 10,9 & 12,3 & 8,5 & 3,1 & 0,00 & 0,00 & 0,00 & 0,00 & 47,00 \\
\hline C.V. (\%) & 429,3 & 185,2 & 99,8 & 60,8 & 52,9 & 62,1 & 122,2 & 356,0 & - & - & - & - & 56,4 \\
\hline Prob* & 0,06 & 0,47 & 0,67 & 0,88 & 0,88 & 0,82 & 0,68 & 0,15 & 0,00 & 0,00 & 0,00 & 0,00 & 0,97 \\
\hline
\end{tabular}

Fuente: Elaboración propia. Prob*: Probabilidad en tantos por uno.

Figura $\mathrm{N}^{\circ} 6$

Evolución del número mensual de días con nieve, SD mensual media y SD mensual máxima a $1.700 \mathrm{~m}$ estimados por el modelo WRF-FSM

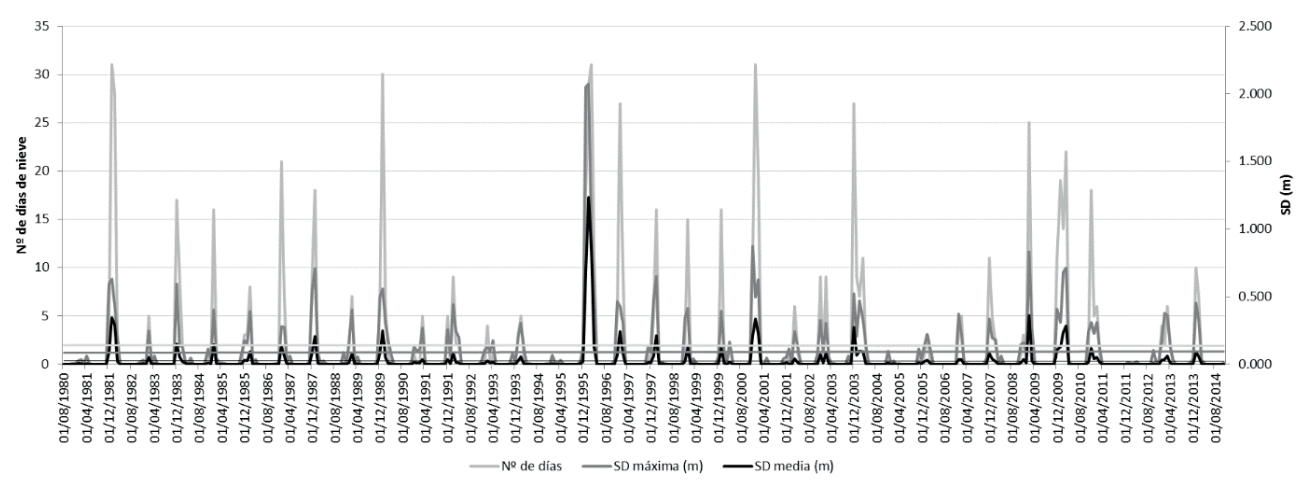

Fuente: Elaboración propia. 


\section{Complementariedad de la teledetección y el modelo WRF-FSM para analizar la dinámica del manto de nieve en una pequeña cuenca hidrológica}

Los trabajos publicados por Alonso-González et al. $(2017,2018)$ y Navarro-Serrano et al. (2017) afrontan la validación de los resultados del modelo WRF-FSM a partir de los datos de los satélites NOAA y especialmente MODIS a escala regional en la Península Ibérica. La comparación entre porcentaje de días con nieve por píxel entre MODIS y WRF-FSM muestra un coeficiente de determinación alto y significativo $\left(R^{2}=0,76\right)$, para el conjunto de la España peninsular, con un error absoluto medio de 5,6\% en los píxeles que registran más de un $5 \%$ de días con nieve al año (18 días al año) (Alonso-González et al., 2017). No obstante, cuando la validación se realiza comparando sistemas montañosos con características diferentes en relación a su extensión, latitud y altitud, los resultados son más heterogéneos (los altos coeficientes de Los Pirineos contrastan con los más bajos de Sierra Nevada), atribuyéndose esta circunstancia a la diferencia de superficie entre ambos sistemas montañosos, ya que la resolución del píxel del modelo WRF-FSM puede resultar muy grosera en las zonas menos extensas (Navarro-Serrano et al, 2017).

En la cuenca objeto de estudio la comparación de los resultados derivados del modelo WRFFSM con los de las técnicas de teledetección expuestos en el apartado anterior presenta a priori varios inconvenientes. El primero y principal es el relativo a la escala espacial, ya que el píxel del modelo WRF-FSM $(9,78 \times 9,78 \mathrm{~km})$ incluye los 266 píxeles de MODIS y los 55 de NOAA que están dentro del perímetro de la superficie de la cuenca de Hoyos del Espino. Ello plantea la pregunta de si el resultado del modelo WRF-FSM integra o no la variabilidad espacial de la cubierta de nieve en los $66,44 \mathrm{~km}^{2}$ de la cuenca. En principio, este problema puede afrontarse en parte con la posibilidad de extraer la información del píxel en intervalos altitudinales de $100 \mathrm{~m}$, lo cual permite la desagregación espacial de los resultados. Sin embargo, persiste la incertidumbre derivada de las distintas orientaciones de la superficie del terreno en el supuesto de zonas onduladas, ya que el modelo asume que la topografía es plana para el conjunto del píxel. En el caso de la zona de estudio, la cuenca está orientada al norte, siendo ésta una de las claves para explicar por qué el número de días con nieve estimado con los sensores de teledetección supera a los estimados por el modelo. El segundo problema radica en que cada técnica mide distintos atributos del manto de nieve, cuya comparación puede resultar más compleja de lo que en un principio pudiera parecer. Con la teledetección estimamos la superficie del manto de nieve, mientras que con el modelo WRF-FSM estimamos la profundidad del manto de nieve (SD), la cantidad de agua equivalente (SWE) y, aplicando determinados umbrales en estas dos variables, el número de días con presencia de nieve en la cuenca. Deducir el número de días con nieve en la cuenca a partir de estas dos técnicas, y comparar los resultados de ambas, debe considerar el hecho de que no tiene por qué existir una correlación positiva entre superficie del manto de nieve y profundidad del mismo.

Con estas limitaciones podemos intentar analizar la complementariedad de algunos de los resultados obtenidos a partir de los productos de teledetección con los extraídos del píxel del modelo WRF-FSM. Para ello hemos procedido a comparar el número mensual de días con nieve extraídos del producto MOD1OA1 con el estimado por el modelo WRF-FSM en diferentes intervalos altitudinales para el período 1/09/2000-30/09/2014, excluyendo del análisis de correlación aquellos meses con valor 0 en las dos series. A pesar de que ambas variables estén relacionadas de forma positiva, con correlaciones significativas a partir de los $1.600 \mathrm{~m}$, los gráficos incluidos en 
la Figura $N^{\circ} 7$ muestran un claro sesgo a favor de MODIS, que parece claramente sobreestimar el número de días con nieve en la cuenca. Llama la atención el apreciable número de meses en los que MODIS detecta presencia de nieve y el modelo no, correspondiendo esas situaciones a los meses de octubre, noviembre, abril y mayo en buena parte de los casos.

Figura $\mathrm{N}^{\circ} 7$

Análisis de correlación entre el número mensual de días con nieve extraídos del producto MOD10A1 y del WRF-FSM para diferentes intervalos altitudinales
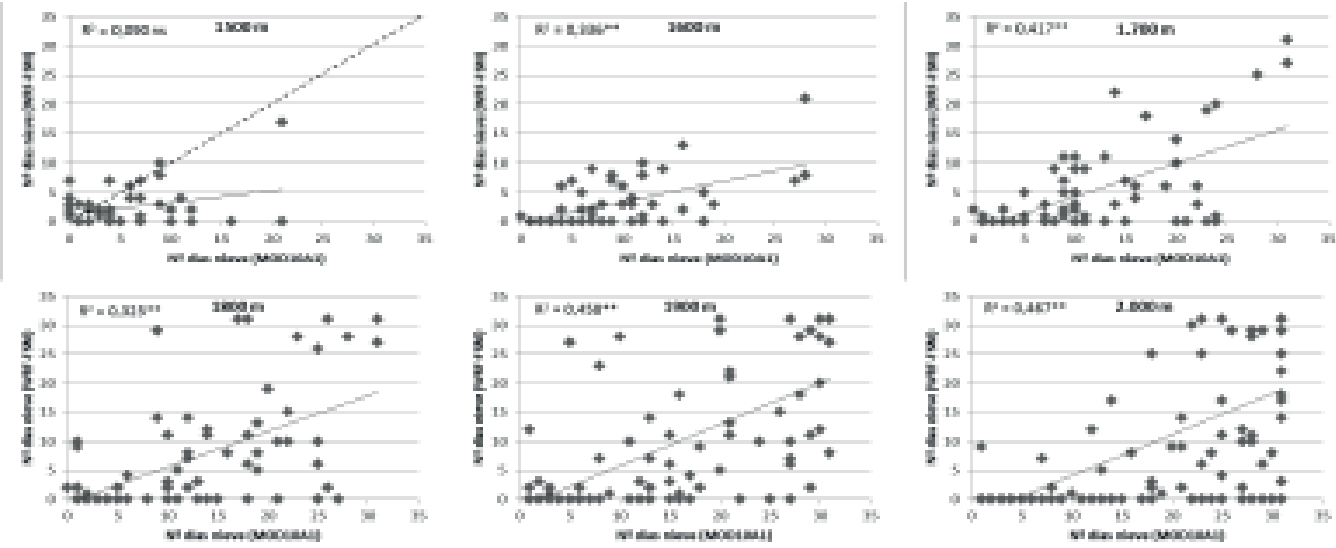

Fuente: Elaboración propia. ${ }^{* *}$ : valor-p $<0,01$, ns: no significativo.

A partir de las series anteriores se puede comparar la distribución mensual de los días con nieve para observar la estacionalidad de la innivación (Figura $N^{\circ} 8$ ). Es evidente la linealidad que existe entre altitud y número de días con nieve, que ya comentamos en el caso del Cuadro $\mathrm{N}^{\circ} 4$, y de la tendencia de MODIS a sobreestimar la presencia de nieve prolongando el período de innivación en todas las altitudes de noviembre a abril (6 meses), frente a los 4 que estima el modelo WRF-FSM, y registrando un mayor número de días de nieve en todos los meses.

Figura $\mathrm{N}^{\circ} 8$

Distribución mensual del número de días con nieve estimados con el modelo WRF-FSM y el producto MOD10A1 para el período 01/09/2000-30/09/2014

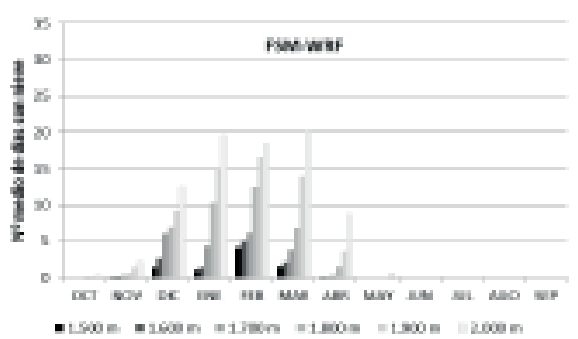

Fuente: Elaboración propia.

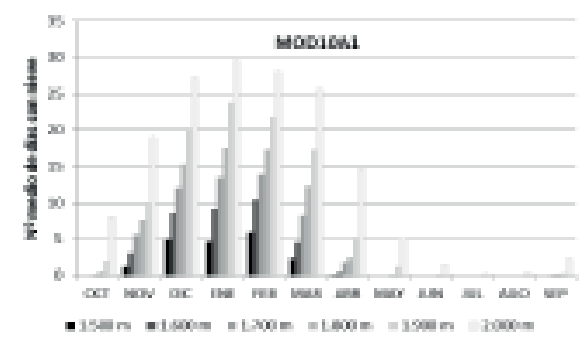

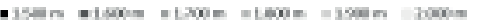


Asumiendo la disparidad de las técnicas aplicadas para estimar la dinámica del manto de nieve, las diferencias en la escala espacial, la diversidad de variables en las que se expresan los resultados de las estimaciones y el reducido número de meses en que las series de datos se solapan, la Figura $N^{\circ} 9$ sintetiza buena parte de lo expuesto en este apartado mostrando el reparto de la superficie media mensual del manto de nieve extraída de los dos productos de teledetección más fiables (NOAA y MODIS) y el número medio mensual de días con nieve a $1.700 \mathrm{~m}$ a partir del modelo WRF-FSM y del sensor MODIS. El análisis utiliza los datos mensuales correspondientes al período común (1/09/2000-30/09/2009). La información principal que puede extraerse del gráfico es que todos los datos apuntan a acotar el período importante de innivación en los meses de diciembre, enero, febrero y marzo, con la existencia de un pequeño ciclo que consistiría en una acumulación importante de nieve en la cuenca en diciembre, debido a la ocurrencia de al menos 7 días de nieve que cubrirían casi una tercera parte de la superficie, una leve inflexión en enero, para de nuevo recuperar en febrero la situación de diciembre y, finalmente, experimentar una acusada reducción del número de días de nieve y extensión del manto durante el mes de marzo, debido al aumento de las temperaturas.

Figura $\mathrm{N}^{\circ} 9$

Distribución mensual de la superficie media del manto de nieve $\left(\mathrm{km}^{2}\right)$ estimada por los sensores NOAA y MOD102A y del número medio mensual de días con nieve estimado por el producto MOD10A1 y el modelo WRF-FSM a $1.700 \mathrm{~m}$.

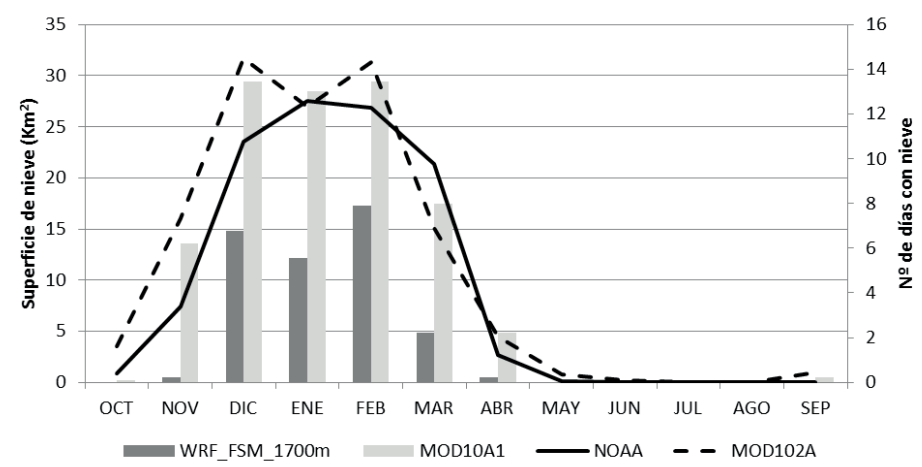

Fuente: Elaboración propia.

\section{Influencia del manto de nieve en la respuesta hidrológica de la cuenca}

Trabajos publicados previamente sobre la respuesta hidrológica de la cuenca seleccionada apuntaron un cambio de régimen fluvial, debido a la pérdida de importancia del pico nival primaveral en el hidrograma, como consecuencia de una reducción de las precipitaciones y una subida de las temperaturas en los meses de febrero y marzo (Ceballos-Barbancho y Morán, 2006; Ceballos-Barbancho et al., 2008). Desde esta perspectiva, con los nuevos datos disponibles puede abordarse el análisis del papel de la nieve acumulada durante el período de innivación invernal (diciembre-marzo) en las aportaciones hídricas de la cuenca (Figura $N^{\circ} 10$ ), según se indicó en el 
apartado de Metodología. Con independencia del período interanual que analicemos (Figura $\mathrm{N}^{\circ}$ $10 \mathrm{~A}, \mathrm{~N}^{\circ} 10 \mathrm{C}$ y $\mathrm{N}^{\circ} 10 \mathrm{E}$ ), la correlación entre precipitaciones y caudales es alta y significativa para el conjunto de meses abril-junio, ya que las precipitaciones explicarían al menos el $60 \%$ de los caudales registrados. El análisis de la correlación de los residuos de P vs. Q con la nieve acumulada durante los meses de mayor innivación es muy desigual según la variable que utilicemos como indicador de la influencia de la nieve. La Figura $N^{\circ} 10 B$ muestra la relación entre los residuos con la cantidad de agua equivalente (SWE) estimada por el modelo WRF-FSM, a 2.000 m.s.n.m. en el mes de marzo, con un coeficiente de determinación significativo $\left(R^{2}=0,53\right)$. Este resultado sugiere que en aquellos años en los que los caudales observados son altos, en relación a la precipitación caída, la diferencia se explicaría por una mayor acumulación (y posterior fusión) de nieve durante el

Figura $N^{\circ} 10$

Análisis de correlación entre precipitaciones y caudales de los meses de abril, mayo y junio en distintos períodos ( $A, C$ y E) y entre los residuos de $P$ vs. Q con la cantidad de SWE (B), cobertura de nieve estimada con MODIS (D) y NOAA (F) del mes de marzo.
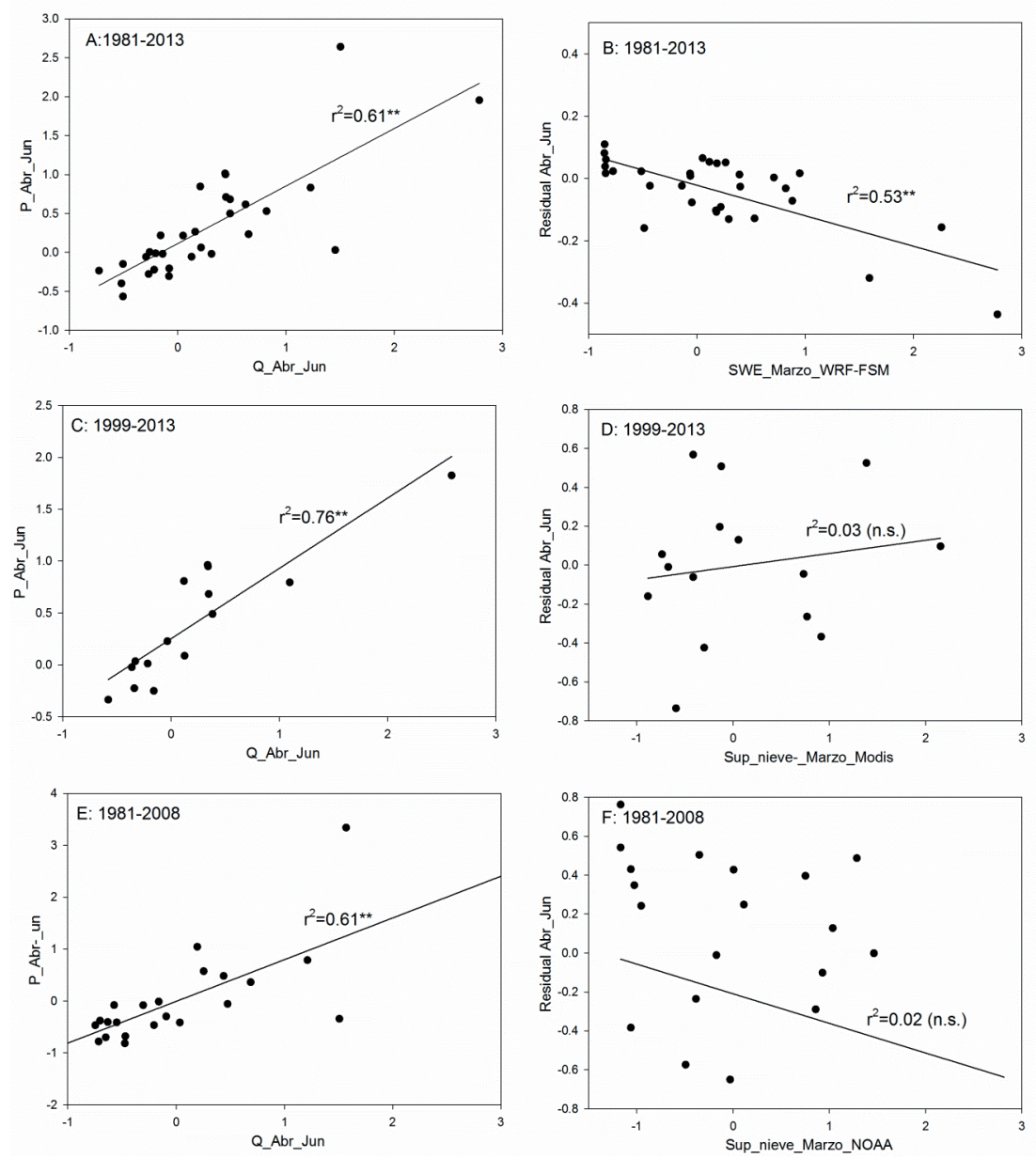

Fuente: Elaboración propia. **: valor-p < 0,01, ns: no significativo. 
invierno; mientras que en los años en donde observamos caudales más bajos, en relación con las precipitaciones de la primavera, la explicación estaría en una menor cantidad de nieve acumulada durante el invierno y en la capacidad de la cuenca de infiltrar y evapotranspirar una proporción significativa de la lluvia caída. Si utilizamos la superficie de nieve en la cuenca como dato integrador de la innivación durante la estación invernal, no encontramos ninguna correlación significativa con los residuos de P vs. Q (Figura $\mathrm{N}^{\circ} 10 \mathrm{D}$ y $\mathrm{N}^{\circ} 10 \mathrm{~F}$ ). La circunstancia de que la correlación entre cubierta de nieve y contenido de agua no sea lineal explica que la cubierta de nieve no sea un buen indicador de las reservas de agua disponibles durante el período de fusión nival.

\section{Conclusiones}

Los resultados del presente trabajo muestran la utilidad de la teledetección y modelos de balance energía para estudiar la estacionalidad y dinámica temporal del manto de nieve en una cuenca hidrográfica de tamaño pequeño, ante la dificultad y coste que supone la instalación de dispositivos de medición en el campo.

Entre los productos de teledetección disponibles, los derivados de las series de NOAA y MODIS ofrecen una mayor garantía en sus resultados debido a la apreciable correlación y menor sesgo entre sus series de datos. El análisis de la cobertura media mensual de nieve en la cuenca alta del Tormes, a partir de las estimaciones de NOAA y MODIS, permite delimitar con claridad el período de innivación entre los meses de diciembre y marzo. A pesar de la acusada irregularidad interanual de temperaturas y precipitaciones en la zona de estudio, propia de un clima mediterráneo, en estos cuatro meses la probabilidad de nevadas oscila entre el 90 y el 100\% cubriendo como mínimo el $20 \%$ de la superficie total de la cuenca. En el caso de las series anuales, éstas no muestran ninguna tendencia significativa en la evolución de la superficie del manto de nieve en las dos últimas décadas del siglo pasado y en la primera del presente siglo, y sí una marcada irregularidad.

Si con la teledetección se ha delimitado el período de innivación (número de días con nieve en la cuenca) a partir de la estimación de la superficie del manto de nieve; con el modelo WRFFSM se ha hecho a partir del análisis de la profundidad del manto de nieve y la cantidad de agua equivalente. Los resultados de la comparación entre el número de días con nieve estimados con ambas técnicas son estadísticamente significativos, aunque se observa una tendencia clara por parte de la teledetección a estimar un mayor número de días con nieve en la cuenca. A pesar de ello, el resultado del análisis de la estacionalidad y de la evolución del manto de nieve extraído del modelo permite llegar a unas conclusiones muy parecidas a las de la teledetección. Los resultados del modelo apuntan un comportamiento muy lógico de la innivación en la cuenca, ya que conforme aumenta la altitud el número medio mensual y total anual de días con nieve es mayor y decrece de forma apreciable su variabilidad interanual. El período de innivación realmente importante en la cuenca ocurre entre los meses de diciembre y marzo, que suman más del $90 \%$ de los días con nieve en todas las franjas altitudinales. Como ya ocurriera con las series de NOAA y MODIS en el caso de la cubierta de nieve, la evolución de variables como número mensual de días con nieve o la profundidad del manto de nieve tampoco muestra ningún tipo de tendencia, manifestándose de nuevo una acusada irregularidad interanual en todas ellas. 
Considerando el contexto geográfico de la zona de estudio, estos resultados pueden aplicarse en campos muy diversos a la hora de conocer mejor los recursos del medio y la gestión de los mismos. Por ejemplo, la viabilidad económica de estaciones de esquí, de la explotación ganadera de los pastos de alta montaña -dependientes del agua de fusión-, la fenología de muchas especies de plantas y animales -dependientes de la ocurrencia de agua en las zonas más altas durante el verano- $y$, sobre todo, la generación y estacionalidad de caudales que discurren por la red hidrográfica. Actualmente, con las series de datos disponibles sobre el manto de nieve, puede evaluarse de forma más precisa el papel de la cantidad de nieve acumulada durante el invierno sobre los caudales generados en primavera (meses de abril, mayo y junio) debido a los procesos de fusión. Los resultados preliminares de este trabajo muestran la utilidad del modelo WRF-FSM para analizar el papel del manto de nieve en la respuesta hidrológica de la cuenca alta del río Tormes en relación a la información aportada por los sensores de teledetección. Ante la imposibilidad de las técnicas de teledetección de estimar el espesor del manto y, por tanto, del volumen de nieve existente en el inicio del período de fusión, ahora está disponible como alternativa la cantidad de agua equivalente (SWE) estimada por el modelo WRF-FSM. En el contexto de la problemática creciente que supone la disponibilidad de recursos hídricos en las zonas mediterráneas, en un escenario de cambio global, el manejo de herramientas de previsión como las series simuladas con WRF-FSM puede tener una gran importancia de cara a conocer mejor la respuesta de aquellas cuencas con presencia de nieve en sus tramos de cabecera.

\section{Referencias bibliográficas}

ALONSO-GONZÁLEZ, E.; LÓPEZ-MORENO, J.I.; NAVARRO-SERRANO, F.; SANMIGUEL-VALLELADO, A. y CEBALLOS-BARBANCHO, A. Simulando el manto de nieve en la Península lbérica para el período 1980-2014. En: RUIZ-FERNÁNDEZ, J.; GARCÍA-HERNÁNDEZ, C.; OLIVA, M.; RODRÍGUEZ-PÉREZ, C. y GALLINAR, D. Ambientes periglaciares: avances en su estudio, valoración patrimonial y riesgos asociados. Oviedo: Servicio de Publicaciones de la Universidad de Oviedo, 2017, p. 193-198.

ALONSO-GONZÁLEZ, E.; LÓPEZ-MORENO, J.I.; GASCOIN, S.; GARCÍA-VALDECASAS, M.; SANMIGUEL-VALLELADO, A.; NAVARRO-SERRANO, F.; REVUELTO, J.; CEBALLOS-BARBANCHO, A. \& ESSERY, R. Daily gridded datasets of snow depth and snow water equivalent for the Iberian Peninsula during 1980-2014. Earth System Science Data, 2018, №10, p. 303-315.

ARGÜESO, D.; HIDALGO-MUÑOZ, J.M.; GÁMIZ-FORTIS, S.R; ESTEBAN-PARRA, M.J.; CASTRO-DÍEZ, Y.; ARGÜESO, D. \& GÁMIZ-FORTIS, S.R. Evaluation of WRF Mean and Extreme Precipitation over Spain: Present Climate (1970-99). Journal of Climate, 2012, Vol. 25, № 14, p. 4883-4897.

ATIF, I.; MAHBOOB, M.A. \& IQBAL, J. Snow cover area change assessment in 2003 and 2013 using MODIS data of the Upper Indus Basin, Pakistan. Journal of Himalayan Earth Sciences, 2015, Vol. $48, N^{\circ} 2$, p. $117-128$.

AZORÍN-MOLINA, C.; BAENA-CALATRAVA, R.; ECHAVE-CALVO, I.; CORNELL, B.H.; VICENTE-SERRANO, S. \& LÓPEZ-MORENO, J.I. A daytime over land algorithm for computing AVHRR convective cloud climatologies for the Iberian Peninsula and Balearic Islands. International Journal of Climatology, 2013, N³3, p. 2113-2128. 
BARNETT, T.P.; ADAM, J.C. \& LETTENMAIER, D.P. Potential impacts of a warming climate on water availability in snow-dominated regions. Nature, 2005, No 438, p. 303-309.

BEGUERÍA, S.; LÓPEZ-MORENO, J.I.; LORENTE, A.; SEEGER, M. \& GARCÍA-RUIZ, J.M. Assessing the effect of climate oscillations and land-use changes on stream-flow in the Central Spanish Pyrenees. Ambio, 2003, Vol. 33, N 4, p. 283-286.

BENISTON, M.; KELLER, F.; KOFFI, B. \& GOYETTE, S. Estimates of snow accumulation and volume in the Swiss Alps under changing climatic conditions. Theoretical and Applied Climatology, 2003, $N^{\circ} 76$, p. 125-140.

BUISAN, S.; LÓPEZ-MORENO, J.I.; SANZ, M.A. \& KOCHENDORFER, J. Impact of weather type variability on winter precipitation, temperature and snowpack in the Spanish Pyrennees. Climate Research, 2016, N69, p. 79-92.

CEBALLOS-BARBANCHO, A. y MORÁN-TEJEDA, E. Evolución de las portaciones hídricas en una cuenca de montaña del Sistema Central: cabecera fluvial del río Tormes (1941-2004). Cuadernos de Investigación Geográfica, 2006, №32, p. 7-28.

CEBALLOS-BARBANCHO, A.; MORÁN-TEJEDA, E.; LUENGO-UGIDOS, M.A. \& LLORENTE-PINTO, J.M. Water resources and environmental change in a Mediterranean environment: The south-west sector of the Duero river basin (Spain). Journal of Hydrology, 2008, N 351, p. 126-138.

CORNWELL, E.; MOLOTCH, N.P. \& MCPHEE, J. Spatio-temporal variability of snow water equivalent in the extra-tropical Andes Cordillera from distributed energy balance modeling and remotely sensed snow cover. Hydrology and Earth System Sciences, 2016, №20, p. 411-430.

DANKERS, R. \& DE JONG, S.M. Monitoring snow cover dynamics in Northern Fennoscandia with SPOT VEGETATION images. International Journal of Remote Sensing, 2004, № 25, p. 2933-2949.

DIETZ, A.J., KUENZER, C., GESSNER, U. \& DECH, S. Remote sensing of snow - a review of available methods. International Journal of Remote Sensing, 2012a, Vol. 33, No 13, p. 4094-4134.

DIETZ, A.J.; WOHNER, C. \& KUENZER, C. European snow cover characteristics between 2000 and 2011 derived from improved MODIS daily snow cover products. Remote Sensing, 2012b, № 4, p. 2432-2454.

DOZIER, J. Spectral signature of alpine snow cover from the Landsat Thematic Mapper. Remote Sensing of Environment, 1989, № 28, p. 9-22.

ESSERY, R. A factorial snowpack model (FSM 1.0). Geoscience Model Development, 2015, Vol. 8, $N^{\circ} 12$, p. 3867-3876.

ESTRELA, T. y FRANCÉS, M. Datos sobre la nieve y los glaciares en las cordilleras españolas. El programa ERHIN (1984-2008). Madrid: Ministerio de Medio Ambiente y Medio Rural y Marino, 2008. 
FASSNACHT, S.R.; SEXSTONE, G.A.; KASHIPAZHA, A.H.; LÓPEZ-MORENO, J.I.; JASINSKI, M.J.; KAMPF, S.K. \& VON THADEN, B.C. Deriving snow-cover depletion curves for different spatial scales from remote sensing and snow telemetry data. Hydrological Processes, 2016, Vol. 30, № 11, p. 1708-1717.

FAYAD, A.; GASCOIN, S.; FAOUR, G.; LÓPEZ-MORENO, J.I.; DRAPEAU, L.; LE PAGE, M. \& ESCADAFAL, R. Snow hydrology in Mediterranean mountain regions: A review. Journal of Hydroly, 2017, $N^{\circ} 551$, p. 374-396.

FAYAZ, N.; VAZIFEDOUST, M. \& ARAGHINEJAD, S. Monitoring of snow cover variation using MODIS snow product. International Archives of Photogrammetry, Remote Sensing and Spatial Information Sciences, 2013, N 40, p.165-168.

GARCÍA-RUIZ, J.M.; LÓPEZ-MORENO, J.I.; VICENTE-SERRANO, S.M.; LASANTA-MARTÍNEZ, T. \& BEGUERÍA, S. Mediterranean water resources in a global change scenario. Earth-Science Review, 2011, Vol. 105, N³, p. 121-139.

GARCÍA-VALDECASAS OJEDA, M.; GÁMIZ-FORTIS, S.R.; CASTRO-DÍEZ, Y. \& ESTEBAN-PARRA, M.J. Evaluation of WRF capability to detect dry and wet periods in Spain using drought índices. Journal of Geophysical Research: Atmospheres, 2017, Vol. 122; N³, p. 1569-1594.

GASCOIN, S.; HAGOLLE, O.; HUC, M.; JARLAN, L.; DEJOUX, J.F.; SZCZYPTA, C.; MARTI, R. \& SÁNCHEZ, R. A snow cover climatology for the Pyrenees from MODIS snow products. Hydrology and Earth System Sciences, 2015, Nº 19, p. 2337-2351.

GILABERTE-BURDALO, M.; LOPEZ-MARTIN, F.; PINO-OTIN, M.R. \& LOPEZ-MORENO, J.I. Impacts of climate change on ski industry. Environmental Science \& Policy, 2014, N 44, p. 51-61.

HUBANKS, P.A.; KING, M.D.; PLATNICK, S. \& PINCUS, R. MODIS algorithm theoretical basis document no. ATBD-MOD-30 for level-3 global gridded atmosphere products. NASA, 2008.

LASANTA, T.; LAGUNA, M. \& VICENTE-SERRANO, S.M. Do tourism-based ski resorts contribute to the homogeneous development of the Mediterranean mountains? A case study in the Central Spanish Pyrenees. Tourism Management, 2007, N²8, p. 1326-1339.

LI, X.; FU, W.; SHEN, H.; HUANG, C. \& ZHANG, L. Monitoring snow cover variability (2000-2014) in the Hengduan Mountains based on cloud-removed MODIS products with an adaptive spatio-temporal weighted method. Journal of Hydrology, 2017, N 551, p. 314-327.

LLORENTE-PINTO, J.M.; NAVARRO-SERRANO, F.J.; ALONSO-GONZÁLEZ, E. y CEBALLOS-BARBAN$\mathrm{CHO}, \mathrm{A}$. Evolución reciente del manto de nieve en la España peninsular. En: ALLENDE, F.; CAÑADA, R;, FERNÁNDEZ-MAYORALES, G.; GÓMEZ, G.; LÓPEZ, N.; PALACIOS, A.; ROJO, F. y VIDAL, M.J. Naturaleza, territorio y ciudad en un mundo global. Madrid: Universidad Autónoma de Madrid, Asociación de Geógrafos Españoles, 2017, p. 200-209.

LÓPEZ-MORENO, J.I. \& GARCÍA-RUIZ, J.M. Influence of snow accumulation and snowmelt on streamflow in the central Spanish Pyrenees. Hydrological Sciences Journal, 2004, Vol. 49, №5, p. 787-802. 
LÓPEZ-MORENO, J.I.; GOYETTE, S.; VICENTE-SERRANO, S.M. \& BENISTON, M. Effects of climate change on the intensity and frequency of heavy snowfall events in the Pyrenees. Climatic Change, 2011, No 105, p. 489-508.

MARCHANE, A.; JARLAN, L.; HANICH, L.; BOUDHAR, A.; GASCOIN, S.; TAVERNIER, A.; FILALI, N.; LE PAGE. M.; HAGOLLE, O. \& BERJAMYE, B. Assessment of daily MODIS snow cover products to monitor snow cover dynamics over the Moroccan Atlas mountain range. Remote Sensing of Environment, 2015, $\mathrm{N}^{\circ} 160$, p. 72-86.

MASKEY, S.; UHLENBROOK, S. \& OJHA, S. An analysis of snow cover changes in the Himalayan region using MODIS snow products and in-situ temperature data. Climatic Change, 2011, N 108 , p. 391-400.

NAVARRO-SERRANO, F.M.; ALONSO-GONZÁLEZ, E.; SERRANO-NOTIVOLI, R.; SANMIGUEL-VALLELADO, A.; AZORÍN-MOLINA, C. y LÓPEZ-MORENO, J.I. Análisis comparativo de la superficie cubierta por nieve obtenida a partir de imágenes NOAA-AVHRR, MODIS-MOD10A1 y del modelo FSM-WRF. En: RUIZ-FERNÁNDEZ, J.; GARCÍA-HERNÁNDEZ, C.; OLIVA, M.; RODRÍGUEZ-PÉREZ, C. y GALLINAR, D. Ambientes periglaciares: avances en su estudio, valoración patrimonial y riesgos asociados. Oviedo: Servicio de Publicaciones de la Universidad de Oviedo, 2017, p. 199-206.

RIGGS, G.A.; HALL, D.K. \& SALOMONSON, V.V. MODIS snow products user guide to collection 5. NASA, 2006.

RIGGS, G.A. \& HALL, D.K. MODIS Snow Products Collection 6 User Guide. National Snow and Ice Data Center, 2015.

SAAVEDRA, F.A; KAMPF, S.K.; FASSNACHT, S.R. \& SIBOLD, J.S. Changes in Andes snow cover from MODIS data, 2000-2016. The Cryosphere, 2018, N 12, p. 1027-1046.

SANMIGUEL-VALLELADO, A.; MORÁN-TEJEDA, E.; ALONSO-GONZÁLEZ, E. \& LÓPEZ-MORENO, J.I. Effect of snow on mountain river regimes: an example from the Pyrenees. Frontiers of Earth Science, 2017, Vol. 11, N³, p. 515-530.

SKAMAROCK, W.C.; KLEMP, J.B.; DUDHIA, J.; GILL, D.O.; BARKER, D.M.; DUDHA, M.G.; HUANG, X.; WANG, W. \& POWERS, J.G. Description of the Advanced Research WRF Version 3. NCAR Tech. Note NCAR/TN-475+STR. NCAR. Boulder: National Center for Atmospherie Research, 2008. Disponible en Internet: http://opensky.ucar.edu/islandora/object/technotes:500

SPROLES, E.A.; KERR, T.; ORREGO NELSON, C. \& LOPEZ ASPE, D. Developing a snowmelt forecast model in the absence of field data. Water Resources Management, 2016, Vol. 30, No 7, p. 25812590 .

STEHR, A.; LINK, O. \& AGUAYO, M. Using MODIS imaginery to validate the spatial representation of snow cover extent obtained from SWAT in data-scarce Chilean Andean watershed. In: BODOQUE, J.M.; SMITH, C. \& SRINIVASAN, R. International SWAT Conference. Book of Abstract. Ciudad Real: Universidad de Castilla-La Mancha, 2011, p. 58. 
STEHR, A. \& AGUAYO, M. Snow cover dynamics in Andean watersheds of Chile (32.0-39.5S) during the years 2000-2016. Hydrology and Earth System Sciences, 2017, № 21, p. 5111-5126.

VAN PELT, W.J.J.; KOHLER, J.; LISTON, G.E.; HAGEN, J.O.; LUKS, B.; REIJMER, C.H. \& POHJOLA, V. A. Multidecadal climate and seasonal snow conditions in Svalbard. Journal of Geophysical Research: Earth Surface, 2016, № 121, p. 2100-2117.

VERBYLA, D.; HEGEL, T.; NOLIN, A.W.; VAN DE KERK, M.; KURKOWSKI, T.A. \& PRUGH, L.R. Remote sensing of 2000-2016 alpine spring snowline elevation in Dall Sheep Mountain Ranges of Alaska and Western Canada. Remote Sensing, 2017, Vol. 9, N 11, p. 1157.

WRZESIEN, M.L.; DURAND, M.T.; PAVELSKY, T.M.; HOWAT, I.M.; MARGULIS, S. A. \& HUNING, L. S. Comparison of methods to estimate snow water equivalent at the mountain range scale: a case study of the California Sierra Nevada. Journal of Hydrometeorology, 2017, No 18, p. 1101-1119.

WU, X.; SHEN, Y.; WANG, N.; PAN, X.; ZHANG, W.; HE, J. \& WANG, G. Coupling the WRF model with a temperature index model based on remote sensing for snowmelt simulations in a river basin in the Altay Mountains, north-west China. Hydrological Processes, 2016, № 30, p. 3967-3977.

XIAO, X.; SHEN, Z. \& QIN, X. Assessing the potential of VEGETATION sensor data for mapping snow and ice cover: a Normalized Difference Snow and Ice Index. International Journal of Remote Sensing, 2001, № 22, p. 2479-2487. 